Fall 11-23-2020

\title{
COVID-19: Best Practices and the Way Forward
}

Juliana Nwauwa

University of St. Augustine for Health Sciences, j.nwauwa@usa.edu

DOI: https://doi.org/10.46409/sr.RRAC3924

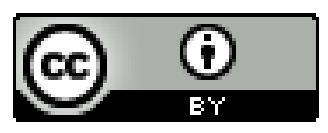

This work is licensed under a Creative Commons Attribution 4.0 License.

Follow this and additional works at: https://soar.usa.edu/scholprojects

Part of the Public Health and Community Nursing Commons, Public Health Education and Promotion Commons, Respiratory Tract Diseases Commons, and the Virus Diseases Commons

\section{Recommended Citation}

Nwauwa, J. (2020). COVID-19: Best Practices and the Way Forward. [Doctoral project, University of St. Augustine for Health Sciences]. SOAR@USA: Student Scholarly Projects Collection.

This Scholarly Project is brought to you for free and open access by the Student Research at SOAR @ USA. It has been accepted for inclusion in Student Scholarly Projects by an authorized administrator of SOAR @ USA. For more information, please contact soar@usa.edu, erobinson@usa.edu. 
COVID-19: Best Practices and the Way Forward

\title{
COVID-19: Best Practices and the Way Forward
}

\author{
Juliana Nwauwa, DNP, MSN, APRN, FNP-BC \\ School of Nursing, University of St. Augustine for Health Sciences \\ This Manuscript Partially Fulfills the Requirements for the \\ Doctor of Nursing Practice Program and is Approved by: \\ Kathleen Farrell, DNSc, RN
}

November 23, 2020 


\section{University of St. Augustine for Health Sciences DNP Scholarly Project \\ Signature Form}

\begin{tabular}{|c|c|c|}
\hline $\begin{array}{l}\text { Student Last Name: } \\
\text { Nwauwa }\end{array}$ & $\begin{array}{l}\text { First Name: } \\
\text { Juliana }\end{array}$ & $\begin{array}{r}\text { Middle Initial: } \\
\text { C }\end{array}$ \\
\hline \multicolumn{3}{|l|}{ E-mail: } \\
\hline $\begin{array}{l}\text { Title of DNP Project: } \\
\qquad \text { COVID-1 }\end{array}$ & COVID-19: Best Practices and the Way Forward & \\
\hline \multicolumn{3}{|c|}{$\begin{array}{l}\text { My signature confirms I have reviewed and approved this final written DNP Scholarly Project. } \\
\text { DocuSign electronic signature or wet signature required. }\end{array}$} \\
\hline Type Name in Blue Box Below & Signature & Date \\
\hline $\begin{array}{l}\text { DNP Project Primary Faculty: } \\
\text { Kathleen Farrell, DNSc, RN }\end{array}$ & Kathleen Farrell & $11 / 23 / 2020$ \\
\hline $\begin{array}{l}\text { DNP Project Preceptor: } \\
\text { N/A }\end{array}$ & & \\
\hline $\begin{array}{l}\text { DNP Project Preceptor: } \\
\text { N/A }\end{array}$ & & \\
\hline
\end{tabular}




\begin{abstract}
COVID-19 is a global health emergency that originated in Wuhan, China, in December 2019. It was declared a pandemic on March 11, 2020, and since then has affected more than 53,507,282 individuals and claimed the lives of more than 1,305,164 around the globe. It is a respiratory virus transmitted from person to person through airborne aerosols and droplets from infected individuals and direct contact with infected surfaces. Numerous factors, such as socioeconomic status, population density, pre-existing health conditions, and lack of health insurance, have contributed to the disproportionate impact of COVID-19 among certain demographic groups. The COVID-19 impact ranges from family disruptions, school closures, business closures, economic impact, international travel, and trade disruptions. COVID-19 is still evolving as new evidence is being identified. Preventive measures, such as using personal protective equipment (PPE), hand hygiene, social distancing, and avoiding large group gatherings, have been shown to help reduce the spread of COVID-19. With remdesivir being the only approved treatment of COVID-19, supportive treatments have been implemented to help the patient with moderate to severe symptoms while efforts for vaccine production and availability are still in progress. A national and global approach to preventive measures is recommended with increased healthcare access, especially to high-risk populations, and expanded educational awareness for improved population health. Healthcare leaders, government, and private healthcare agencies, policymakers, and legislators are urged to adopt these recommendations to improve the COVID-19 pandemic response and be prepared for future health emergencies.
\end{abstract}

Keywords: COVID-19, Pandemic, Preventive measures, supportive care and treatment, vaccine, recommendations. 


\section{Table of Contents}

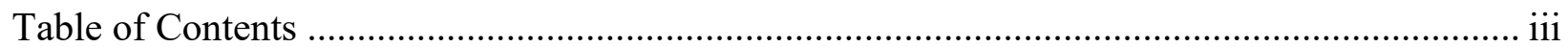

Background and Scope of the Problem .................................................................................2

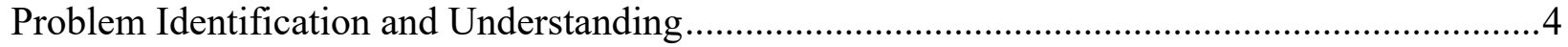

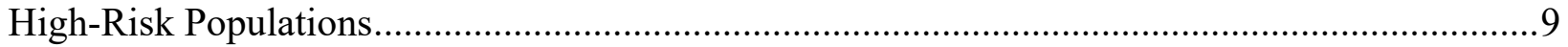

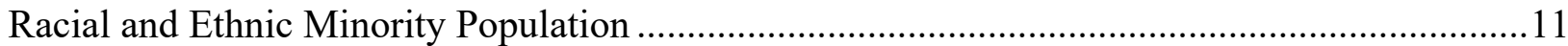

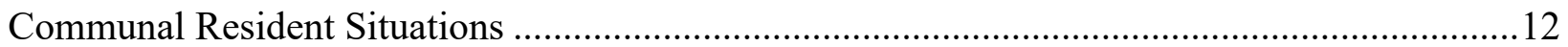

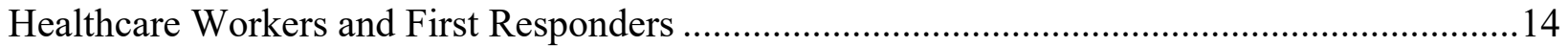

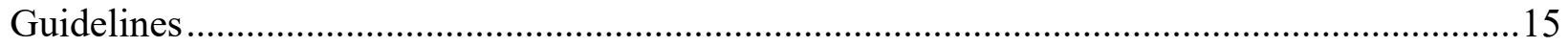

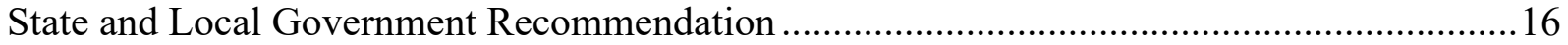

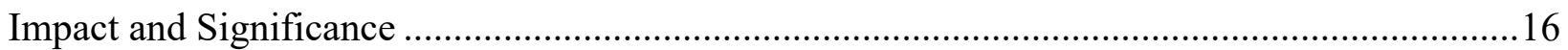

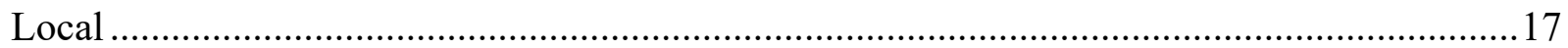

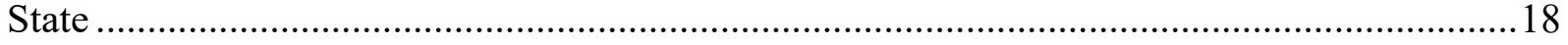

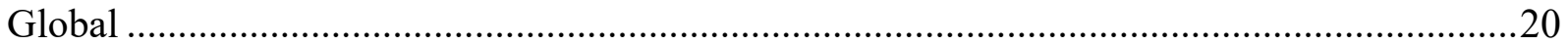

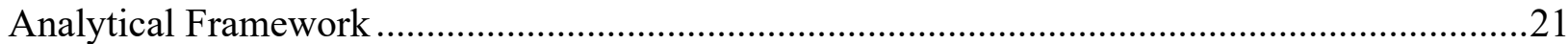

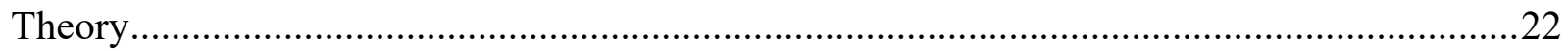

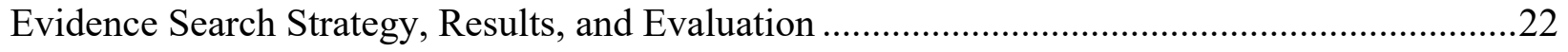

Themes from Evidence Review and Recommendation.................................................23

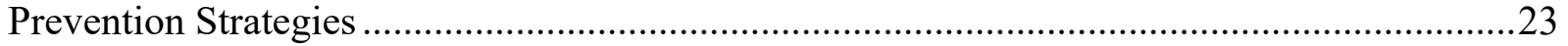

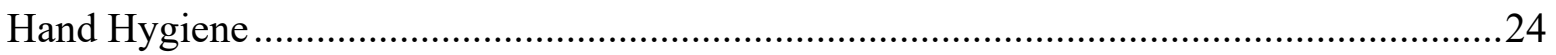




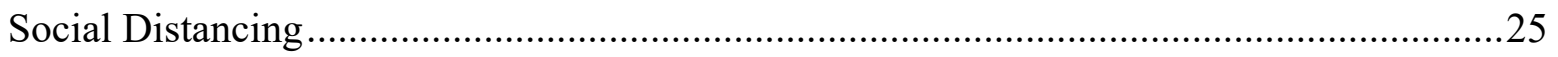

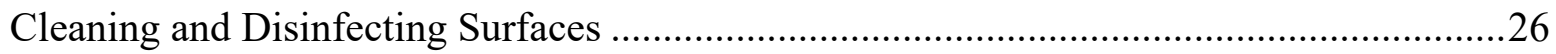

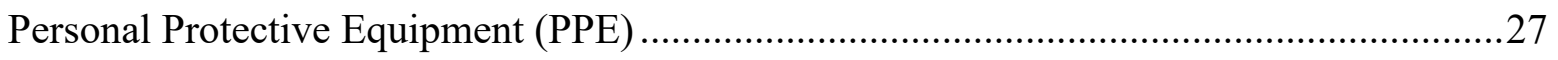

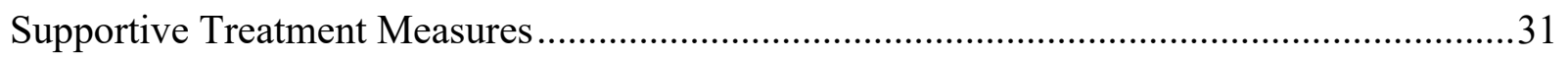

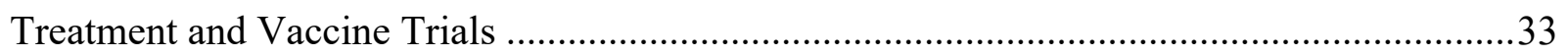

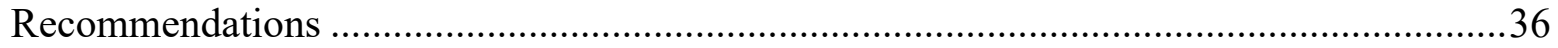

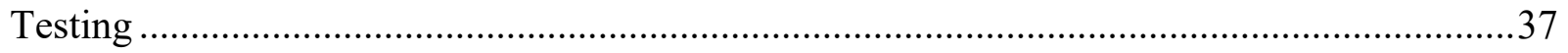

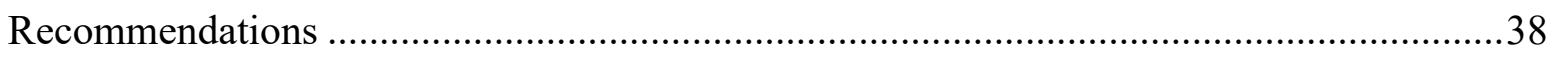

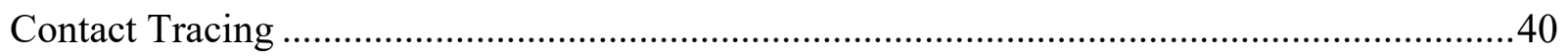

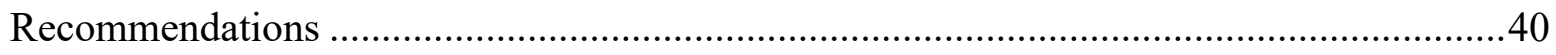

Managing Stress, Mental Health, and Healthcare Access, .............................................42

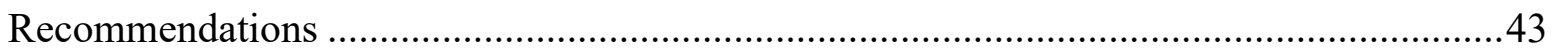

Healthcare Access through Telehealth ........................................................................... 45

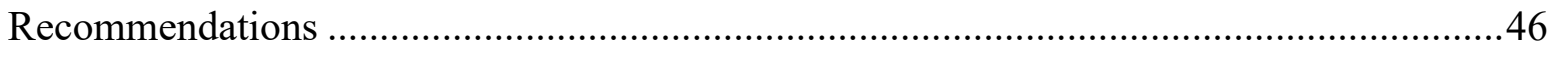

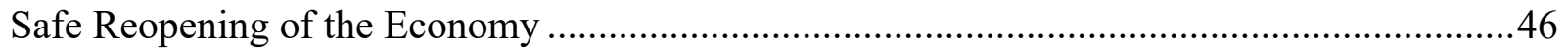

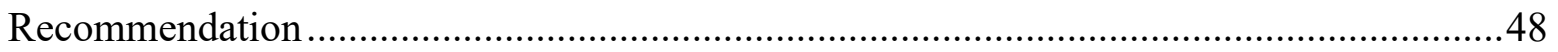

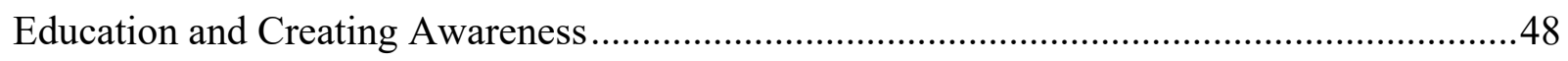

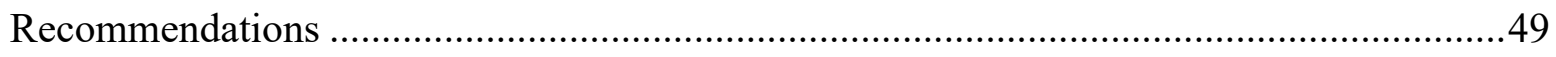

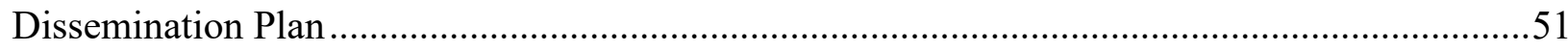

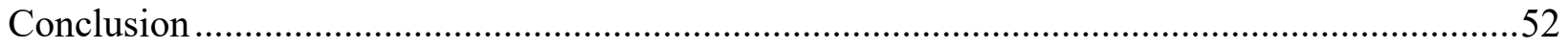




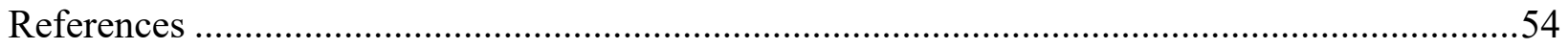

Table 1. Some COVID-19 Signs and Symptoms, and Complications..........................................67

Table 2. John Hopkins Evidence Level ..............................................................................68

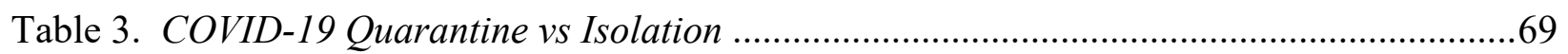

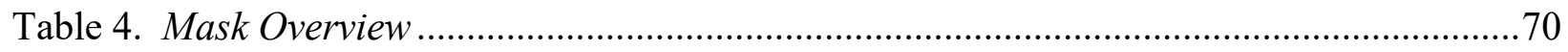

Table 5. Airborne and Droplet Isolation ………………........................................................

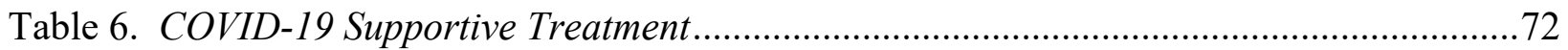

Table 7. Comparison of RNA and Some Standard Vaccines .....................................................73

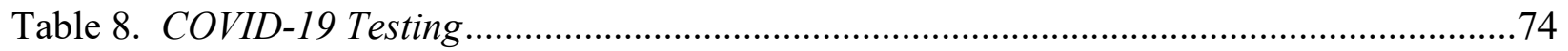

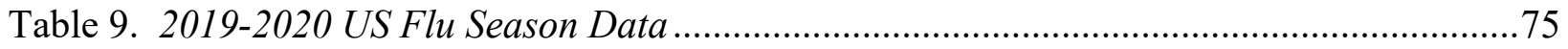

Figure 1. Global Trend of COVID-19 from February to September 2020 ................................76

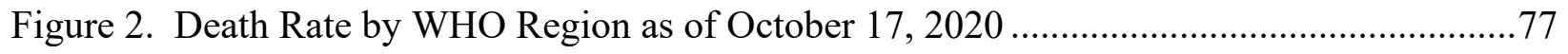

Figure 3. COVID-19 Confirmed Cases by WHO Region from February to September 2020 ....78

Figure 4. COVID-19 Deaths by WHO Region from February to September 2020 ......................79

Figure 5. COVID-19 Trend in Confirmed Cases: Top 12 Countries from February to September 2020

Figure 6. COVID-19 Trend in Most Deaths: Top 12 Countries from February to September 2020

Figure 7. COVID-19 Coinfection Respiratory Pathogens............................................................82

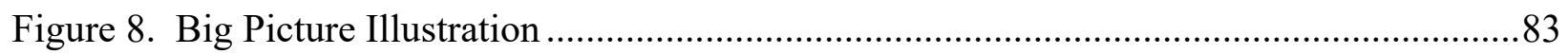




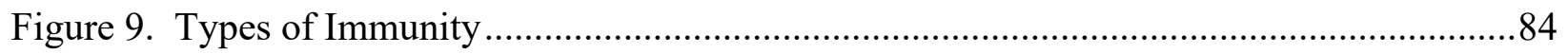

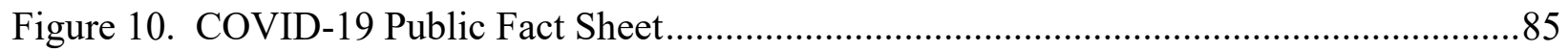

Figure 11. COVID-19 Healthcare Provider Fact Sheet..............................................................86

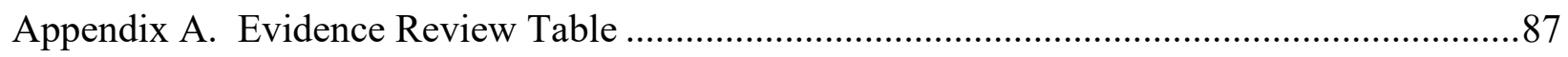




\section{COVID-19: Best Practices and the Way Forward}

The Coronavirus disease (COVID-19) has had a tremendous impact on global health since identified in Wuhan, China, in December 2019. Since its detection, the health effects of contracting COVID-19 have changed the way individuals, families, communities, and entire countries are forced to live and function. During this period of adjustment to the COVID-19 restrictions, new knowledge about the virus pandemic evolves.

Disparities have also affected the severity and impact of the COVID-19 on specific demographic groups, with a disproportionate burden of illness and death suffered by race, ethnicity, region, and income (Centers for Disease and Control and Prevention (CDC), 2020c). In September 2020, the CDC reported that the black or African Americans were five times as likely and Latinos eight times as likely to die from COVID-19 related complications than their white non-Hispanic peers (CDC, 2020c). Numerous factors include socioeconomics, population density, pre-existing health conditions, and lack of health insurance, which places these vulnerable populations at a disproportionately high risk of contracting and dying from COVID19.

There is a need for healthcare providers to develop strategies and best practices to improve the health and wellness of individuals, families, and communities devastated by this virus. Such practices include but are not limited to the availability of personal protective equipment (PPE), maintaining social distancing, contact tracing, equitable access to testing methods, and treatments. The COVID-19 pandemic has affected the local, state, national, and international world differently. As of November 15, 2020, the World Health Organization (WHO) reported an estimate of 53,507,282 confirmed cases of COVID-19, with 1,305,164 deaths, and the death rate is at 2.4\% (WHO, 2020e). Strategies and best practices for improving 
the community response to COVID-19 worldwide should be adopted and implemented. This health policy analysis will examine the evidence and recommend actions as the best way forward to address society's health care needs during this COVID-19 pandemic and beyond.

\section{Background and Scope of the Problem}

COVID-19 is an infectious disease caused by the novel coronavirus transmitted from person to person via airborne aerosol or droplets and contact with infected surfaces (WHO, 2020c). The droplets from the mouth and the nose during sneezing, coughing, and talking contribute to the virus's fast spread, causing increased morbidity and mortality among the infected individuals. These droplets have also accounted for the transmission of COVID-19 through the mucous membranes of the eyes (conjunctiva) and mouth (oral route) (Mick \& Murphy, 2020). There has been some misunderstandings and controversy regarding the transmission of COVID-19 through the airborne route. Morawska \& Cao (2020) explained that after droplets are released, the droplets' liquid content starts to evaporate, making them smaller than air current gravitational force. With their viral contents carried freely in the air, these smaller droplets known as aerosols can travel meters and tens of meters to infect other individuals through airborne transmission, especially in the absence of adequate ventilation (Morawska \& Cao, 2020).

According to WHO (2020d), the COVID-19 outbreak was declared a public health emergency of international concern on January 30, 2020. Since the disease has spread worldwide, it was declared a global pandemic on March 11, 2020. The WHO (2020e) reported 53,507,282 confirmed cases of COVID-19 as of November 15, 2020, with the Americas (North, Central, and South Americas) having the highest number $(22,960,102)$, followed by Europe $(14,792,945)$ and South-East Asia in the third place with 10,015,731 confirmed cases. A total of 
$1,305,164$ deaths were also reported simultaneously as of November 15,2020. The highest number of deaths $(675,735)$ came from the Americas (WHO, 2020e).

The mortality rate of COVID-19 has been monitored and traced monthly, which provided critical epidemiological data. Looking at the cumulative trend worldwide (see Figure 1), the mortality rate peaked in April at $7.2 \%$ and has decreased to $2.4 \%$ as of November 15,2020 . The WHO region's confirmed cases, deaths, and death rate as of October 17, 2020, showed a surge in the number of confirmed cases, although with lower deaths and death rates in all regions, affecting population health (see Figure 2). Monitoring the death rate of COVID-19 provides essential information about how severe the pandemic continues to be, and it is a crucial indicator of continuous efforts to mitigate this pandemic. The WHO regions and individual country's data (see Figures 3, 4, 5, and 6) about the confirmed cases and the number of deaths were traced at the end of every month. The data shows certain distinct regions and countries with very high numbers, which likely reflects the trend in the widespread activity of the virus and the effectiveness of prevention strategies. The data calls for continuous action to mitigate the spread, morbidity, and mortality of COVID-19 globally.

The spread of COVID-19 from country to country reflects the interconnectedness of each country around the globe. There are individual movements from one country to the other for trade, leisure, and healthcare. This movement makes it difficult to contain the spread of contagious diseases in a location, area, or country without completely sealing off the borders; therefore, it provides the basis for the importance of a global effort to address global health issues such as the COVID-19 pandemic. Rudnicka et al. (2020) stated that the global health community needs to take action to slow the continual spread, morbidity, and mortality of 
COVID-19. Implementing global public health measures to detect, prevent, and respond to health issues, including an infectious disease outbreak, is paramount to combat the problem.

There are inequalities in countries' capacity to prevent, detect, and respond to outbreaks, which creates challenges in controlling the spread of infectious diseases from one country to the other. In their analysis, Kandel et al. (2020) noted that only half of the analyzed countries have strong operational readiness in place for health emergencies. They stated that strengthening the global readiness for outbreak control, capacity building, and collaboration between countries is needed (Kandel et al., 2020). Multiple approaches using financial, legislative, and executive actions are needed to control the spread of COVID-19. These will involve the participation of all segments of the society, both the public and the government.

\section{Problem Identification and Understanding}

According to the WHO, on December 31, 2019, pneumonia of unknown origin was reported in Wuhan's city in the Hubei province, China. The virus was believed to have originated from bats to anteater-like animals called pangolins before crossing over to humans (Rahhal, \& Dyer, 2020). The WHO branch in China closely monitored this virus. The spread of COVID-19 to other countries within one month prompted the WHO officials to develop a strategic preparedness and response plan (SPRP) with a $\$ 675$ million fund from the United States covering the months of February through April (WHO, 2020d). The purpose of the SPRP was to protect countries with weaker healthcare systems vulnerable to the virus outbreak. The SPRP covers the areas of international coordination, readiness to research, and innovation aimed to provide early care, limit transmission, minimize social and economic impacts, and communicate essential information (WHO, 2020d). The national governments, multilateral organizations, 
private foundations, philanthropies, and other donors coordinated efforts to assists the WHO in funding this initiative.

Some factors have contributed to COVID-19 spread from the origin in Wuhan, China. Little was known about this new disease until its widespread impact around the globe. It was believed that international travel for trade, leisure, and other businesses had contributed to the rapid spread of COVID-19 as well as poor hand hygiene and close contact. Tracing how COVID-19 has spread, the Cambridge University scientists identified three virus strains causing COVID-19 across the globe. Two strains were traced to have spread to the United States of America (USA) (Rahhal, \& Dyer, 2020). They noted that the original strain of the virus from Wuhan China spread to the West Coast in the USA and also affected Japan and Australia (Rahhal, \& Dyer, 2020). Different strains mutated from the original strain spread in China before moving on to Europe and the East Coast in the USA to New York, and as well as to Canada (Rahhal, \& Dyer, 2020). The COVID-19 virus was believed to have been in New York circulating unknown for weeks before being diagnosed due to the presence of asymptomatic cases that is still a big challenge currently (Rahhal, \& Dyer, 2020). Efforts to reduce the spread of COVID-19 require measures to mitigate spread from asymptomatic carriers as individuals move across each spread region.

The travel data from December 2019 and January 2020 shows that before China was banned from entering the United States (US) on January 31, 759,493 people had entered from China (Rahhal, \& Dyer, 2020). The European countries were not banned at the same time. China was banned from entering the United States, even when data shows some isolated cases in Europe in late January. This inconsistent act allowed millions of people to enter the US from European countries such as Italy, Spain, and Britain. The same issue happened to many countries 
worldwide. The inability to seal off the borders completely provided the channel for infected symptomatic and asymptomatic individuals to move across different countries spreading COVID-19. Experts stated that, although the virus mutates, the newer strains do not appear to be more deadly than the original strain. The virus mutates very slowly, with only slight differences between different strains (Rahhal, \& Dyer, 2020). This slight difference is vital information that affects the development of vaccines and treatment approaches worldwide to deal with the COVID-19 pandemic.

Community spread of COVID-19 was reported as confirmed cases of COVID-19 in the community continue with no history of recent travel or known source of exposure. Crowded situations, close physical contact, enclosed space, and long duration of exposure are the factors that may increase community spread (CDC, 2020c). The epidemiology of COVID-19 is becoming more apparent as estimates of transmissibility, severity, and researchers are continuously refining the population affected. COVID-19 is efficiently transmitted in the community with an increased number of asymptomatic carriers (Mayo Clinic, 2020a). With this knowledge of asymptomatic COVID-19 patients spreading the infection in the community unknowingly, measures to mitigate the potential widespread COVID-19 need to be addressed. Timely implementation of measures such as banning mass gatherings, temporary school closures, the mandatory wearing of masks, appropriate disinfection and/or hygiene measures, and isolation of ill persons reduced mortality in several US cities during the 1918-1919 influenza pandemic (Cowling \& Aiello, 2020). Vigilant adherence to these measures is even more vital in our present small and easily assessable global world. Ensuring effective implementation of mitigation measures continuously and timely in the community will reduce the community spread of COVID-19. 
Covid-19 symptoms vary from one individual to another. Some patients can be asymptomatic, while some may be pre-symptomatic and symptomatic. Symptoms could be mild or severe and may lead to severe complications and possibly death.

Studies with large samples have estimated that 1.2-12.9\% of COVID-19 patients are asymptomatic. In comparison, smaller sample studies have the number at $87.9 \%$, noting that the asymptomatic patients remain a potential source of COVID-19 spread in the community (AlSadeq \& Nasrallah, 2020). Being asymptomatic does not mean one cannot spread the virus, and asymptomatic patients can have complications from having COVID-19. Studies have shown that asymptomatic patients have shown some inflammatory lung abnormalities such as striped shadows or ground-glass opacities on a CT scan, and a pulmonologist and critical care physician at a New York hospital in Brooklyn (Huang, 2020) noted the same. Some of the most common symptoms (see Table 1) include fever, tiredness, and dry cough, nasal congestion, body aches and pains, headache, sore throat, conjunctivitis, diarrhea, loss of smell or taste, and skin rash or discoloration of fingers or toes (CDC, 2020b; WHO, 2020b).

Cutaneous manifestations have also been noted mostly in children and young adults but were also seen in older adults. Some of these lesions appear popular and reddish like chilblains, become more purpuric, and flattens within a week (Landa et al., 2020). The location of COVID19 lesion presents in different locations such as the toes (COVID toes), soles, fingers, or heel. It can be seen in both symptomatic and asymptomatic COVID-19 patients (Landa et al., 2020). Kawasaki-like symptoms such as non-purulent conjunctivitis, polymorphic rash, mucosal changes, and swollen extremities were also noted in children five to seven and a half years old, although fewer of these classic symptoms were noted in a few older children (Viner and Whittaker, 2020) 
New onset of confusion, flushed lips or face, and an inability to wake or stay awake have also been reported, and symptoms may appear two to fourteen days after exposure to the virus (CDC, 2020b). Some of the complications of COVID-19 (see Table 1) include pneumonia with shortness of breath, heart problems, multiple organ failure, blood clots, and other bacterial and viral superimposed infections. A study by Chen et al. (2020) identified that Acinetobacter baumannii and Klebsiella pneumonia are among the pathogens identified in Covid-19 positive patients' cultures. Another study by Xing et al. (2020) identified the most common COVID-19 coinfection caused by respiratory pathogens (see Figure 7) to be influenza virus A (60.00\%). Influenza virus B (53.30\%), mycoplasma pneumonia (23.30\%), and Legionella pneumophila $(20.00 \%)$.

Having comorbidities contributes to severe complications from COVID-19 as the individual's immune system and the effect of specific treatment may aid the infection's progression. The study done by de Lucena et al. (2020) concluded that individuals with cardiometabolic diseases such as hypertension and diabetes were at an increased risk of complications from COVID-19 due to increased immune response dysregulation.

Some studies have raised the issue of Angiotensin-Converting Enzyme (ACE), and ACE 2 receptor overexpression as the COVID-19 virus enters the cell, aiding the rapid multiplication of the virus in the infected individual's body cells (de Lucena et al., 2020). To understand further the role of ACE2 in inactivating the ligands for the bradykinin receptors, Roche and Roche (2020) explained that the COVID-19 virus enters host cells through the transmembrane protein receptor (ACE2) in the lung tissue, decreasing its activities. Kinins are molecular protein fragments that help lower blood pressure and allow fluid to leak out of the blood vessels. Experts believed that the depletion of ACE2 activities by COVID-19 caused dysregulation in the 
inactivation of the desArg9 bradykinin (the ligands of B1R), worsening local vascular leakage in the lung tissue leading to pulmonary infiltrate and difficulty breathing (Van de Veerdonk et al., 2020).

Rapid multiplication of the COVID-19 virus also generates an excessive inflammatory response with the release of pro-inflammatory cytokines, causing cytokines storm, which harms and rapidly destroys healthy cells (de Lucena et al., 2020). Exploring and targeting this bradykinin system may present a new and great therapeutic window as COVID-19 treatment options continue to be researched.

\section{High-Risk Populations}

Although Covid-19 can affect anyone with mild to severe symptoms or no symptoms, certain factors put some individuals at a higher risk of complications and possibly increased mortality. Older people or individuals with existing chronic medical conditions, such as lung disease, heart disease, diabetes, chronic kidney or liver disease, severe obesity, or those with compromised immune systems, may be at higher risk of poor outcome and serious complications from contracting Covid-19 (Mayo Clinic, 2020a). It is important to note that people without risk factors also succumb to COVID-19, affecting all gender and age groups.

Different age groups respond to COVID-19 differently. Older adults and people with comorbidities may have severe symptoms and more complications from COVID-19 than younger and healthy adults may. Some children are mostly asymptomatic, but they could also be affected sometimes with less severe symptoms, although in some cases, they can quickly progress to respiratory distress syndrome (Dong et al., 2020). Children have also presented with some symptoms resembling Kawasaki syndromes, as previously mentioned. However, a new childhood inflammatory disorder referred to as multisystem inflammatory syndrome in children 
(MIS-C) was identified (Levin, 2020). This disorder is rare but occurs two to four weeks after contracting COVID-19 in patients below 21 years of age, with a high proportion noted among black, south Asian, and Hispanic patients (Levin, 2020). The MIS-C can be severe with cardiovascular manifestation, and most have recovered with intensive care management with a range of immunomodulatory agents (Levin, 2020). Knowledge of all these COVID-19 presentations and variations is essential for managing patients and minimizing spread and complications.

There has been some research regarding COVID-19 virus transmission in utero, especially knowing that in the past other viral infections such as rubella and Zika included placental infection and transmission. A recent study showed a newborn baby reported positive for COVID-19. The mother, who tested positive post-birth with a viral test known as reverse transcription-polymerase chain reaction (RT-PCR) nasopharyngeal anal swabs, identified the E and S gene of the COVID-19 virus (Vivanti et al., 2020). A study of the maternal placenta tissue identified a small amount of key cell surface receptors and high ACE2. The ACE2 allows the COVID-19 virus to enter the cells and replicate (Vivanti et al., 2020; Wang et al., 2020).

COVID-19 in neonates can cause cerebral vasculitis leading to neonatal viremia, fever, pneumonia, and neurological symptoms including lethargy, vomiting, irritability, axial hypertonia, and opisthotonos (Vivanti et al., 2020). Zeng et al. (2020) recommended that screening pregnant women and implementing stricter infection control measures, quarantining infected mothers, and closely monitoring neonates at risk of COVID-19 be implemented strictly. Knowledge of these new developments will help develop effective preparedness in the care of pregnant patients and their newborns to minimize complications. 


\section{Racial and Ethnic Minority Population}

Racial and ethnic groups have been noted to be disproportionately affected by the COVID-19 pandemic. In the documentary, Pandemic: A Nation Divided presented by the WGN news in Chicago, Illinois, the Latino race was noted to have an increased infection rate. However, the black race was noted to have an increased number of deaths from COVID-19 disease, and the same data is seen in multiple states across the United States of America. This signifies the disparity associated with the Covid-19 disease, where Latinos in some states were most affected, and some other states have the blacks most affected. The impact of COVID-19 has divided the country in a very significant way depending on race and ethnicity. The black and brown communities have been dealing with disparities in healthcare services provision, coupled with a lack of access to healthy food, suitable housing, well-equipped hospitals, health centers, and inequality in providing the needed healthcare services. These issues have long placed this population to have multiple comorbidities that may affect an individual's response to COVID-19 if contracted.

Underlying health conditions and lower access to care are the primary cause of poor outcomes related to health care disparity. This disparity increases racial and ethnic minority groups' vulnerability in public health emergencies such as outbreaks of COVID-19 virus infections. Issues such as not having health insurance and the inability to pay for healthcare services have contributed to poor health with multiple comorbidities among the black and Hispanic communities. According to the CDC (2020c), individuals with no health insurance are threefold in Hispanics and double in African Americans than Caucasians. All these factors have contributed to increased morbidity and mortality among these vulnerable populations when it comes to Covid-19 infections. A higher risk of severe complications from COVID-19 has also 
been noted among Native Americans because they are prone to having diabetes, heart disease, and other conditions (The Harvard Gazette, 2020). This population seems not to have much publicity regarding COVID-19 despite their worsening situation. As of April 30, the thirdhighest per capita rate of COVID-19 in the country is in the Navajo nation, after New Jersey and New York (The Harvard Gazette, 2020).

Employment environments and circumstances could also contribute to the racial and ethnic minority's risk of contracting Covid-19 and being severely sick. Work environments, type of work, and work policies have been unfavorable for this vulnerable population. According to the CDC (2020c), almost 25\% of Hispanic or black workers are employed in service industry jobs that eliminate the possibility of working from home compared to $16 \%$ of non-Hispanic whites. Hispanic workers account for 53\% of agricultural workers (CDC, 2020c), which often lack policies and benefits such as paid sick leave. These factors contribute to employees working even when sick; therefore, this crisis may increase the risk of spreading the COVID-19 virus. There are lower paid sick leave rates in Hispanic workers than white non-Hispanic workers (CDC, 2020c).

\section{Communal Resident Situations}

Living conditions also contribute to the underlying health conditions that will affect how people respond to and prevent the spread of COVID-19. The crowded, living in communal residential situations, has contributed to the rapid spread of the Covid-19 virus among the affected communities. The majority live in a densely populated area such as in jail, assisted living, group homes, shelter, college dormitory, multilevel residences, or multi-generational living conditions. These populations are predisposed to an increased risk of COVID-19 spread due to their inability to practice social distancing. Long-term care facilities residents experienced 
increased mortality rates from COVID-19 due to multiple factors, including living situations and multiple comorbidities. Testing and contact tracing policies, as well as other COVID-19 mitigation policies, should hold strict adherence.

Assisted living facilities, group homes, and shelters were highly affected by COVID-19 due to their congregate living situations and habitats having multiple comorbidities, especially among their elderly population. Given their congregate living situation and the elderly population they serve, there is a high risk of increased spread of COVID-19 with increased morbidity and mortality. The CDC (2020a) has recommended source control measures to limit the spread and severity of COVID-19 in assisted living facilities. Such measures include the prompt identification of the point of contact, which has resulted in visitors' restrictions and screening of residents and staff in assisted living. With the increasing number of asymptomatic cases of COVID-19, the living situations that limit social distancing, and possible quarantining, rapid action is required to identify, isolate, and test residents and others that might have been exposed promptly to prevent further the spread of COVID-19 (CDC, 2020a)

Congregational living in the jails, prisons, and detention areas increases the risk for COVID-19 infection. The living set-up and overcrowded conditions make it very difficult and impossible for the inmates to practice social distancing or quarantine. Incarcerated people are at a significant risk of increased morbidity and mortality from the Covid-19 infection. This required strategies to reduce the jail population, such as releasing those who are not a threat to public safety or are elderly or infirmed (Equal Justice Initiative, 2020). The infection rate of Covid-19 in jails and prisons is about 2.5 times higher than in the general population nationwide (Equal Justice Initiative, 2020). 
Congregational living in jails, prisons, and detention areas are overrepresented by the racial and ethnic minority groups (CDC, 2020c), increasing their risk for COVID-19 infection in these facilities. Multilevel residences or multi-generational living conditions are common among the ethnic and racial minority group and contributes to the inability to protect the elderly and provide proper isolation of the sick ones. As noted by the CDC (2020d), social distancing, which is to reduce physical interaction between people and keeping six feet apart, remains an essential part of the prevention of COVID-19 spread. Unfortunately, the multi-generational living condition makes it impossible for this to happen. The presence of the elderly in such living conditions with co-morbidities worsens the situation.

With school reopening and students going back to college dormitories and crowded classrooms, maintaining social distancing remains a significant challenge. Preventive measures such as wearing a mask, quarantining if exposed, contact tracing, isolating if sick, hand washing, and frequent cleaning of surfaces is recommended (CDC, 2020d).

\section{Healthcare Workers and First Responders}

Healthcare personnel (HCP), including first responders, are at increased exposure to the COVID-19 virus and are dependent upon personal protective equipment (PPE). A total of 90,626 HCP have been reported to have confirmed Covid-19 in the United States as of July 2, 2020. The United States HCP continues to experience widespread cases of Covid-19 (CDC, 2020c). Cases among HCP have increased, and based on available data as of August 24, 2020, 142,935 cases of COVID-19 and 660 deaths from COVID-19 have been reported among HCP (CDC, 2020c). The shortage of PPE's and limited access has posed a great challenge to this population and further increased their risk of contracting COVID-19. According to Emanuel et al. (2020), front-line health workers and others who provide care and those who keep critical infrastructures operating 
should be given priorities to PPE, therapeutics, and vaccines access because they are essential pandemic response.

\section{Guidelines}

Several states, national and international guidelines, and policies related to Covid-19 have centered on ways to prevent and minimize the spread of the Covid-19 virus. Prevention strategies are focused more on preventing the spread of the disease, while treatment alternatives for sick individuals are still under development. Unlike some other countries that follow their national guidelines, different states determine the scope of their prevention guidelines in the United States.

The following are recommendations from the CDC (2020d) and the WHO (2020a); individuals should be aware of how the Covid-19 virus spreads and take the necessary precautions. Symptomatic and asymptomatic COVID-19 positive patients should monitor their temperature, be alert for worsening symptoms, and know when and how to seek medical care. Individuals need to maintain a social distance of six feet, or two meters between each other, especially those with a high risk of severe disease. Staying home as much as possible and avoiding close contact (within about 6 feet, or 2 meters) with sick people or have symptoms of Covid-19 is recommended. It is essential to know that some people may not have symptoms or know that they have COVID-19 and can spread it to others. Large events and gatherings should be avoided, and hands should be washed often with soap and water for at least 20 seconds or at least $60 \%$ alcohol-based hand sanitizer if soap and water are not readily available. People need to avoid touching the face with unwashed hands, cover nose and mouth with a facemask in public spaces, and avoid close contact with one another, such as in grocery stores, especially in continuous community areas. Cloth covering should not be substituted for social distancing. 
They do not recommend masks for children younger than two years of age, unconscious people, those with difficulty breathing, or anyone who cannot remove the mask.

Additional recommendations include instructions to avoid touching eyes, nose, and mouth, cover nose and mouth when sneezing and coughing with an elbow or tissue paper, and safely discard used tissue and wash hands immediately. Do not share glasses, dishes, towels, bedding, and other household items when sick. Daily disinfect and clean high-touch surfaces such as light switches, doorknobs, counters, and electronics used frequently with soap and water and EPA approved cleaning agents for COVID-19. Individuals with COVID-19 symptoms should stay home from work, school, and public areas unless they go for medical care and avoid public transportation as much as possible (CDC, 2020b).

\section{State and Local Government Recommendation}

Local and state governments issued recommendations to reduce the spread of the Covid19 while moving in the direction of the safe reopening of the economy. The Covid-19 pandemic has affected every part of the world in many different ways, and this will require some strategies, innovations, and coordinated resources to return to normal living conditions. In the United States of America, different cities and states have initiated their specific re-opening strategies with different stages tailored to the severity of COVID-19 in the area and progress made toward reducing the spread.

\section{Impact and Significance}

Starting from the early days of the COVID-19 pandemic, there have been changes in the life pattern of individuals, families, communities, and entire countries. Apart from the health effects of contracting the COVID-19 virus and being sick, individuals, communities, and the global world have seen changes in the way they live and function. Since this is a new virus, 
ongoing changes in handling the COVID-19 pandemic have emerged, and a lot is still being learned about the virus. When this pandemic started, the most important goal is to stop or contain the spread, and several strategies were immediately put in place. These strategies include; social distancing, hand washing, and use of PPE to take care of sick people, then staying at home, wearing masks in public, cleaning, and disinfecting surfaces. As the COVID-19 virus infection continues to spread, closing non-essential places and businesses, reducing the number of gathering, canceling large events, closing schools, and restrictions on international travel, were added as more measures reduce the spread. The spread of the COVID-19 virus infection and the strategies being implemented to minimize its spread have affected both the local, national, and international economies in many ways.

\section{Local}

Covid-19 has affected the local communities across every state in the United States. The devastating effects have divided the community leaders as well as the church leaders in most communities. Some individuals and communities are affected and require resources more than others require. There is poor access to healthcare services, as most clinics are closed with no information on how patients can receive care. Personal protective equipment such as masks and gloves are very scarce, especially to the community and long-term care facilities leading to an increased COVID-19 virus spread, morbidity, and mortality. The CDC has implemented mitigation strategies for communities. However, some local communities, especially the racial and ethnic communities, are still struggling with health disparities affecting the efforts to stop the spread. While the communities work to reduce COVID-19 spread, economic, secondary health issues, and social consequences of diseases are also being addressed. Efforts should be community-centered to address the specific needs of different communities. 
Individually, the COVID-19 pandemic has caused unemployment and income loss, increased frustration and suffering, and increased mental health sickness, especially depression and anxiety. Congruently, there has been an increased incidence of violence and addictions to non-recreational drugs and alcohol. Some other illnesses, such as obesity and cardiovascular diseases, have also been rising from increased inactivity. Families are faced with fear and anxiety of separation from loved ones and mourning their loved ones who died from COVID-19 related complications. Lack of PPE remains a great challenge for healthcare professionals and the public as the COVID-19 pandemic continues.

The communities have been greatly affected as schools, local shops, healthcare centers, and private clinics were closed during the stay at home orders. The effects of these closures remain economically devastating in addition to an increase in the effects of health disparities, violence, mental health problems, and addiction. The low socioeconomic and ethnic minority communities are challenged with poor access to healthcare services, inability to maintain social distances due to poor living conditions, and lack of healthy and non-healthy food supply. Limited COVID-19 testing, contact tracing, increased co-morbidities, and the continual spread of COVID-19 has greatly increased the morbidity and mortality rate in these communities.

\section{State}

Statewide, healthcare facilities' operations were disrupted as elective surgeries were being canceled, affecting some health maintenance procedures such as colonoscopy and others that may indirectly affect health. Most hospitals, especially the safety-net hospitals that are already in financial crisis, faced greater financial challenges from loss of outpatient and elective surgery services that influenced their ability to provide resources and pay salaries. Some outpatient clinics closed unexpectedly, with patients having difficulty contacting their provider, affecting 
their ability to receive medical advice or refill their medications. A survey of health care providers, mostly in private practices, revealed significant adverse effects ranging from a decline in visits and clinical activities to a reduction in the health care workforce, with a consequent reduction in revenues associated with economic distress (Song et al., 2020).

Different states are impacted differently depending on the rate of COVID-19 spread and the number of individuals affected. Some states with a limited number of infections did not take aggressive measures. In contrast, some other states such as New York, Illinois, Michigan, and New Jersey, with increased COVID-19, cases, and deaths have implemented severe measures. The measures range from school closing to shelter in place, cancellation of events, closing nonessential business, limiting bars and restaurants to curbside pick and deliveries, and interstate flight limitations. With businesses, casinos, and tribal enterprises closed, Native Americans were left with no or limited resources to run their health clinics and provide for foods. All these measures are to minimize the spread of COVID-19 but, at the same time, have affected the economy greatly. Most states reported spending a huge amount of money on PPEs, ventilators, hiring extra healthcare workers, and building more hospitals and healthcare facilities to care for the surge of COVID-19 patients. However, the shortage and effective distribution of PPEs remains a continuous challenge. Unemployment benefits have added to the financial difficulties as the state shoulders part of the expenditure. These expenditures have put a stretch on the state budget despite some relief from the federal government.

\section{National}

Nationally, the impact has gone from healthcare system limitation on services to the financial effects on infrastructures and business, immigration services hold, and several federal government executive orders. The agricultural sector has seen a decline in the workforce and 
food processing industries affecting certain foods' availability. The CDC has collaborated with the state and local public health departments to issue and update guidelines to follow during this pandemic. The financial burden continues to increase as the pandemic progresses. Providing the stimulus package to help small businesses and provide financial assistance to individuals was helpful but still not enough as the situation worsens. The federal government is faced with a great economic challenge with a worsening infection spread.

\section{Global}

COVID-19 has several national and international impacts, although its severity varies depending on the number of individuals affected and the strategic response implemented. Most countries' economy was crippled as businesses and schools were closed, and the ban on international travel that affected international trades and businesses led to economic difficulties. Efforts to decrease the spread of COVID-19 have led to travel restrictions, border shutdowns, and quarantining, which increases the risk of recession and economic crisis. Nicola et al. (2020) has summarized the effect of COVID-19 on the world economy into primary, secondary, and tertiary sectors. Primary sectors involve industries that are concerned with the extraction of raw material. Secondary sectors deal with the production of finished products. Tertiary sectors include industries that provide services.

Quarantining, social distancing, and travel restrictions have caused a reduced workforce across all economic sectors leading to job loss and major economic difficulties (Nicola et al., 2020). There are shut down in businesses, leading to a decrease in commodities and manufactured products, with a significant increase in medical supplies. Schoolchildren's closure comes with much impact and challenges as schoolchildren were diverted to an online learning platform. Many people struggle to navigate the trending e-learning system. One of the strongest 
predictors of the health and the wealth of a country's future workers is education. There has not been a clear quantification of the impact of long-term school closure on educational outcomes, young people's health, future earnings, and future national productivity (Viner et al., 2020).

Nicola et al. (2020) stated that the road to the recovery of the economy is predicted to belong with many years of economic inactivity. The recovery from the economic, political, and manufacturing sectors will require well-formulated strategies for a successful outcome to address international travel and trade, immigration, migration, and food supply problems. A big picture illustration (see Figure 8) provides a visual overview of the general concept of COVID-19 best practices and the way forward.

\section{Analytical Framework}

In this policy analysis project, a theoretical framework is valuable as it increases the effectiveness of the process and provides guidance for systematic policy analysis (CDC, 2015). The CDC policy analytic framework and Kingdon's multiple-streams theory will guide this analysis project and work toward bringing about the best practices for COVID-19. The framework that will guide the structure of this project is the CDC policy analytical framework. The critical step of the CDC's policy analytical framework includes:

- To identify the policy issue or problem

- Identify solutions for the problem or issues, including identifying and describing the policy options, assessing policy options, and prioritizing policy options.

- Develop a strategy for the adoption of the policy solution (CDC, 2015).

The issue identified is not only the infection with COVID-19 but also the impact it has on the global world. In the second step, the guidelines and recommendations to reduce the spread of COVID-19 were identified. As the infection progresses, specific changes were made to ensure 
that the best practice is being implemented for a successful outcome. Moreover, in the final step, some options and alternatives to the current practice are being explored. Recommendations will be disseminated to the appropriate stakeholders (public, healthcare professionals, consumers, and legislators).

\section{Theory}

The theory that guides this project is Kingdon's multiple-streams theory, which is concerned with the agenda-setting incorporating precise relationships among variables (Walt et al., 2008). In this theory, there is a belief that the public policy process has a random character, with problems, policy, and politics flowing along in independent streams (Walt et al., 2008). The idea is that the streams merging will create a window of opportunity for actions such as policy discussion and adoption to take place. The three streams of the theory remain the three angles that interact as they merge to stimulate beneficial actions, especially in the issue of healthcare policy. In the problem stream, the broad issue or problem facing the global world identified is the COVID-19 pandemic requiring public and private attention. The policy stream incorporates ideas, guidelines, and recommendations on how to deal with the problem of COVID-19. The politics stream involves the political transitions guided by the national mood and social pressure regarding the need to change to improve the problem (Walt et al., 2008). According to Gregg et al. (2018), policy entrepreneurship raises awareness of issues and proactively creating policy alternatives while providing a roadmap for future policy leaders.

\section{Evidence Search Strategy, Results, and Evaluation}

An electronic search of the following databases CINAHL, PubMed, EBSCOhost, and Google Scholar, was used to conduct a literature search. Filters were applied to the selected 
studies written in English. Some evidence was also obtained directly from government websites and grey literature from a credible news source.

Owing to this project topic's nature and timing (COVID-19), most of the articles addressed coronavirus and other viral infections but not the actual virus (SARs CoV-2) that caused COVID-19 were eliminated. The articles were screened with filters, and some exclusions were applied, and 30 articles (see Appendix A) were used for the evidence review. Keywords used: COVID-19 pandemic, Coronavirus protection, Preventing COVID-19 spread; COVID-19 and economic impact, COVID-19 safe reopening, and vaccine trials. John Hopkin's evidence level and quality grade (see Table 2) from Hopkins Medicine (n. d) was used to evaluate some of the articles as level I, II, III, and quality grade A, B, C, while some of the articles were from credible and reputable government websites. Some of the evidence was also obtained from professional organizations' websites and grey literature such as interviews, news, and panels.

\section{Themes from Evidence Review and Recommendation}

This section will identify the themes from the currently available evidence and provide recommendations for actions. The themes identified in this evidence review are; prevention strategies, supportive treatment measures, treatment and vaccine trials, testing, contact tracing, managing stress, mental health and healthcare access, the safe reopening of the economy, and education and creating awareness.

\section{Prevention Strategies}

Preventing the spread of COVID-19 remains the best approach at this time for effective control, as there is no current cure or vaccine available. To reduce the spread of COVID-19, preventive strategies such as hand washing, avoiding close contact, social distancing, covering cough and sneezes, wearing masks, cleaning and disinfecting frequently touched surfaces, and 
wearing appropriate PPE's should be followed (Ashour et al., 2020; CDC, 2020d; Illinois

Department of Public Health (IDPH), 2020; Johns Hopkins Medicine, 2020; Srivastava \& Saxena, 2020; WHO, 2020b). Srivastava and Saxena (2020) added that maintaining good immunity and a healthy diet with vitamins, especially $\mathrm{C}$ and $\mathrm{E}$ and exercises, can help fight infections such as COVID-19. Everyone has a part to play in slowing the spread of COVID-19, as individual behavior remains an essential factor in this regard. Compliance with hand hygiene guidelines, social distancing, cleaning, disinfecting surfaces, and PPE use is vital (Anderson et al., 2020).

\section{Hand Hygiene}

Handwashing remains the single most effective measure to reduce the spread of infections (Canadian Centre for Occupational Health and Safety, 2020) even before the coronavirus infection started. However, unfortunately, it remains a problem for compliance among the public and healthcare professionals. Some specific guidelines on effective handwashing include washing hands often with soap and water for at least 20 seconds. Sixty percent of alcohol-based hand sanitizer may be used if soap and water are not readily available (CDC, 2020d; Srivastava, \& Saxena, 2020; WHO, 2020d).

Recommendation. Mandate the installation of water and soap or hand sanitizers in public places. This is very important as an effort to prevent COVID-19 spread continues. Easy access to the hand sanitation process will help to promote compliance. Public places such as train stations, grocery stores, bars, restaurants, and churches, need to follow an established standard provision for hand hygiene stations to operate and penalties should be given to those not meeting the established standard. The health department and the occupational safety and health administration (OSHA) regulations should mandate this recommendation and follow up with a 
periodic inspection to ensure compliance. Every public place needs to have a station for hand hygiene. Establishing and enforcing a standard will improve compliance with the single most effective measure to reduce the spread of infections.

Another recommendation is to educate and reinforce hand washing for all. Provide continuous education and reminder for the public, from children to adults, using teaching tools, videos, billboards, signposts, and media with a clear and concise message. Professional organizations should set an agenda to address handwashing for all ages, as was done to provide helmets for safety programs or car seats for safe transport program.

\section{Social Distancing}

Certain measures are recommended to reduce the spread of the COVID-19 virus from one individual to another, including maintaining six feet of social distancing. Self-isolation and quarantine (see Table 3) are also recommended (CDC, 2020d; Srivastava, \& Saxena, 2020). Keeping away from large group gatherings will help in social distancing. However, there are situations where maintaining social distancing may seem impossible such as in grocery stores, multi-generational living situations, and shelters. Concerted efforts to maintain safety are encouraged, including hand washing, cleaning and disinfecting surfaces, and wearing a mask. Ensuring a national standard in addressing these preventive measures will be beneficial.

Recommendations. The first is to establish a standardized national framework for infection prevention strategies for current and future health emergencies. The second is to replace the state-by-state guidelines on social gathering and other preventive measures with a national standard for the present and future infectious diseases outbreaks. A national standard to guide the preventive strategies will help to minimize the interstate spread of COVID-19 and help to minimize its impact. Establishing uniform national guidelines is in line with global health 
preparedness that will curb the current pandemic and future challenges. Three DACH countries (Germany, Switzerland, and Australia) that share the same borders in central Europe were very successful compared to other European countries in preventing the negative impact of COVID19 even when faced with the same epidemiology situation (Desson et al., 2020). They implemented a standardized approach to infection preventive strategies to reduce the spread and impact of COVID-19 effectively. The declaration of the national state of emergency in Switzerland and Australia was responded to by shifting the decision-making powers of independent states to the central government (Desson et al., 2020).

East Asian regions such as Taiwan, Japan, and Thailand, and some Central and Eastern European countries such as Czech Republic, Poland, and Ukraine, implemented the national standard of public mask-wearing, contributing to the slowing down of the spread of COVID-19 (Chan, 2020). The standardized approach has proven to be effective. It should be implemented globally by establishing and adopting a framework that will guide and direct uniform national approaches to preventive measures by all the states or regions of a nation. This standard framework will allow measures such as mask-wearing, event restrictions, border closures, shelter in place, schools, restaurants, shops, bar closures, and reopening to be implemented uniformly and timely throughout a nation.

\section{Cleaning and Disinfecting Surfaces}

The CDC has recommended the use of COVID-19 environmental protection agency (EPA) approved cleaning agents in addition to routine cleaning with soap and water. EPAapproved disinfectants against the COVID-19 virus are on the $\mathrm{N}$ list. They can be identified by the EPA registration number on the cleaning agent (EPA, n. d.). Use the tool called List N: Disinfectant for COVID-19, which is found on the EPA website (epa.gov) to identify if the 
cleaning agent is EPA approved for COVID-19. To use this tool, the first two numbers of the first two parts of the registration number on the disinfectant label is entered, and the show result button is selected to see if the disinfectant is among the list (EPA, n. d.). These approved products are not for use on the human body or human consumptions but are for use on surfaces while ensuring that the directions on the labels of the products are strictly followed. Alternate disinfectants such as $70 \%$ alcohol or $1 / 3$ cup of $5.25 \%-8.25 \%$ bleach added to one gallon of water can be used in the absence of EPA-approved disinfectants (CDC, 2020d), but maintaining safety in use and storing of these cleaning products is recommended.

Recommendation. Establish standard policies for cleaning and sanitizing public spaces, including schools and businesses. These standard policies will guide different public places to maintain safety by frequently cleaning areas as recommended using the right cleaning agent. In collaboration with OSHA regulations, health departments should mandate the implementation of this recommendation and conduct a periodic inspection to ensure compliance with a penalty for defaulters.

\section{Personal Protective Equipment (PPE)}

Protection from getting in contact with the SARS-Cov-2 that causes COVID-19 entails using barrier methods to avoid coming in contact with persons who have contracted the virus or are suspected of being infected with the virus. The use of isolation gowns, masks, eye cover, and face shields as PPEs have been recommended for healthcare workers, first responders, and other individuals who are taking care of COVID-19 patients or persons under investigation (PUI) for COVID-19 infection (Johns Hopkins Medicine, 2020; WHO, 2020a). As recent developments have determined, some individuals tested positive for the COVID-19 virus but are asymptomatic; 
therefore, the use of a mask or some kind of face coverings have been recommended (CDC, 2020d).

In the United States, some states do not mandate masks in public, yet other states have mandated that masks be worn publicly. The risk of transmission of COVID-19 was reduced with universal masking due to the number of asymptomatic individuals increases (IDPH, 2020). Some exceptions to general mask-wearing include children under two, individuals that are having difficulty breathing, or people who are unconscious, incapacitated, and unable to remove the mask (CDC, 2020d). The public masking recommendation is still not followed, as there is no standardized national or global policy on wearing specific masks that can offer better protection for all. Some different masks (see Table 4) include a dust mask, cloth mask, surgical mask, an N95 mask, and other respirator masks; although Osborn (2020) noted that cloth masks were not regarded as PPEs.

Recommendations. The first recommendation is to increase the production and distribution of N95 masks, especially to high-risk populations. Second, fund and repurpose small businesses to produce the needed PPE's. Third, provide incentives to drive more businesses to engage in PPE production. Fourth, establish a framework to ensure that PPE's are equitably distributed. The fifth is to make the use of the N95 mask mandatory for all with increased availability and reduced cost. The lack of PPE has jeopardized the community's health as provision and distribution of PPE to the community, group homes, shelter, safety-net hospitals, and nursing homes have faced a vast supply and demand imbalance. Government and private interventions to ensure PPE's continuous availability, especially to these high-risk populations, are recommended. Medical resources should be carefully reexamined to identify potential 
shortages in the COVID-19 pandemic, and efforts to mitigate shortage should be timely instituted.

There is convincing evidence that practices such as wearing a mask and other preventive practices have helped slow the spread of COVID-19 in countries worldwide that have mandated national mask-wearing from the pandemic's early stage. This effective strategy comes with its challenges of availability and access as demand increases. The challenge of limited availability of masks was quickly mitigated by countries like China, who supported small businesses, boosted their local productions of masks and other PPE, and implemented rationing methods for effective distribution (Chan, 2020). It is essential to understand that there is more to the adequate supply of masks and other needed PPE to the public than just considering the stock. Chan (2020) stated that for mask supply to be sufficient, it has to enhance local manufacturing capacity, set up distribution networks, timely replenish stocks, and ensure equity and affordability of access.

Some East Asia region implemented grass-root initiated mask making and used their digital infrastructures to ration mask distribution, ensuring equity and affordability of access while supporting local businesses to boost production (Chan, 2020). An example is Taiwan using its national insurance health record database to develop a rationing system for a successful mask distribution (Lee, 2020). Here in the United States, the Medicare system could reach high-risk populations and provide a covered mask and PPE distribution services. Some other parts of Central and Eastern Europe also initiated grass-root mask making with financial assistance and incentive for businesses that repurposed their businesses' line to boost mask production (Chan, 2020). These strategies have proven to be successful in other countries and should be adopted for the present and in the event of other future emergencies. Apart from funding and giving 
incentives, collaborating with private and other government organizations, especially within the communities, to establish small PPE production businesses will boost supply.

With the recent developments in airborne transmission of COVID-19, a more comprehensive approach is needed to protect against the spread of COVID-19. Such approaches will entail adequate protection from airborne COVID-19 RNA particles using an N95 mask. A study by Mick \& Murphy (2020) recognized airborne transmission during aerosolized procedures but added that pursed-lip breathing, natural breathing, and cough could also produce aerosols from the high viral loads in the upper aerodigestive tract. Since both symptomatic and asymptomatic COVID-19 positive individuals carry viral loads of COVID-19 virus, adequate protection will be achieved if the N95 mask is mandated and made available to all individuals likely to be exposed to positive patients. A surgical mask may offer some protection level, but N95 masks have 95\% filtering of the virus and offer the most protection (Osborn, 2020). To keep the population protected, using the N95 mask is essential. However, this comes with its challenge of availability and affordability, and as such, the other recommendations to increase availability and affordability need to be implemented.

An air sampling study performed in several hospitals using polymerase chain reaction testing found several positive samples for SARS-CoV-2 genome (RNA) in the air of hospital rooms of infected patients providing more clarity on airborne transmission (Morawska et al., (2020). A systematic review conducted by Bahl et al. (2020) showed that the COVID-19 virus can remain viable for three hours after aerosolization in a COVID-19 infected individual. Based on the weight of combined evidence, airborne precautions are also required with droplet precautions (see Table 5) to maintain the healthcare workers' occupational health and safety and others taking care of the patients with COVID-19. 
Another recommendation is to implement engineering controls in public buildings to protect the public. Following the outcome of their air sampling study, Morawska et al. (2020) recommended that engineering controls be implemented in public buildings such as schools, churches, healthcare facilities, libraries, restaurants, shops, offices, and public transports. This is important based on the current airborne transmission evidence, and it should be combined with other preventive practices to help reduce the spread of COVID-19. The capital layout for this type of engineering control project may be high, but allocating funds just like in the funding for research and development of products and providing tax incentives similar to solar energy writeoffs that the public will help to implement.

\section{Supportive Treatment Measures}

Currently, supportive care measures (see Table 6), are being used to manage patients, while therapeutic trials for COVID-19 medications and other treatments are still in progress. The number of people affected by COVID-19 continues to increase globally. However, more than $80 \%$ have mild symptoms that can be self-managed at home, $20 \%$ lead to severe respiratory compromise, and other complications requiring hospitalization (Bajwah et al., 2020). Providing expert, symptomatic treatment for frail patients with multiple comorbidities to prevent avoidable suffering remains a moral obligation in healthcare. Some of the symptoms (i.e. dry cough) are triggered by the neuro-modulatory changes that heighten the cough reflex sensitivity. This is often acute and self-limiting but intense and requires some supportive management (Bajwah et al., 2020).

Many COVID-19 patients suffer from inflammatory and clotting problems that have been linked to an immune-thrombosis reaction. This immune-thrombosis reaction is due to the upregulation of pro-inflammatory cytokines with marked elevation of D-dimmers triggered by 
the intense stimulation of intrinsic fibrinolysis in the lungs (Thachil, 2020). Antithrombotic therapy for the prevention of venous thromboembolic events is recommended. Heparin is an antithrombotic medication used for its thrombin blocking action and is also used to reduce inflammation (Fogarty et al., 2020; Lodigiani et al., 2020; Thachil, 2020).

Some experts treat bacterial co-infections such as pneumonia in COVID-19 patients with antibiotics. In their systematic review, Lai et al. (2020) stated a possible bacterial co-infection among COVID-19 patients. In a telephone interview, Dr. Richard Prudencio (Internist at Kaiser Permanente, California, June 2020) stated that the facility utilized macrolide antibiotics such as azithromycin as an adjunctive therapy to treat most COVID-19 patients that presented with pneumonia, which was shown to be helpful. Experts believe that macrolides such as azithromycin and clarithromycin have immunomodulatory and anti-inflammatory effects and downregulate pro-inflammatory cytokines (Rizk et al., 2020).

Corticosteroids, as a non-specific immune modulator with potent anti-inflammatory and antifibrotic properties, have drawn more attention in the supportive treatment of COVID-19 patients, particularly in severe cases. A low dose of corticosteroids is believed to play a role in suppressing lung inflammation because it downregulates pro-inflammatory cytokine transcription and improves the dysregulated immune response caused by sepsis, which a possible complication of COVID-19 (Rizk et al., 2020). This downregulation of cytokines prevents extended cytokine response and helps to resolve the systemic and pulmonary inflammation in pneumonia (Rizk et al., 2020). With individualized therapy, steroids such as methylprednisolone (or equivalent) and dexamethasone have contributed to reduced COVID-19 patients' mortality but should be used for a short duration (Zhang et al., 2020). 
Some other supportive treatment for patients has been provided for hypoxia and anxiety seen in a patient with COVID-19. Shortness of breath associated with COVID-19 may lead to severe hypoxia as patients' breathing becomes labored. Depending on the oxygen saturation, the patient may be given oxygen through the nasal cannula. However, in more challenging situations, CPAP/BIPAP or mechanical ventilation may provide oxygen and support ventilation. The difficulty in breathing and the feeling of breathlessness and fear and isolation from significant others may cause anxiety, mild, moderate, or severe. Relaxation technique and breathing exercise can be used for mild anxiety, while moderate to severe anxiety may need to be managed with lorazepam or midazolam medications with good effect (Bajwah et al., 2020). The critically ill patient from COVID-19 and those with complications will require more intense treatments in the intensive care unit with ventilator support and other medications that can sustain their hemodynamic functions.

\section{Treatment and Vaccine Trials}

The identification of medical treatment and the development of therapeutic agents that can help to cure COVID-19 is a critical approach needed to assist those that contract the disease to recover medically. Certain medications have been on trial to treat COVID-19 patients with updates made on the current approach. The FDA issued an update on June 15 to revoke the emergency use authorization (EUA) to use chloroquine and hydroxychloroquine to treat COVID19 patients (National Institutes of Health, 2020). Remdesivir is an antiviral medication that has been on trial use through the FDA EUA for severe cases of hospitalized COVID-19 patients. In a double-blind, randomized, placebo-controlled trial, Beigel et al. (2020) concluded that patients who received remdesivir had a shorter recovery time and were more likely to have earlier improvement than the placebo group. Based on the study data, Beigel et al. (2020) suggested that 
remdesivir treatment may have prevented the progression to more severe respiratory disease and shortened the duration of oxygen and mechanical ventilation use in hospitalized COVID-19 patients. This study's outcome was in line with an earlier randomized trial of remdesivir by Wang et al. (2020) in China that showed a shorter improvement time for hospitalized COVID-19 patients who received remdesivir in a smaller sample size (Beigel et al., 2020). According to the news report on October 22, 2020, the U. S. FDA gave full approval to the use of Gilead's remdesivir as the only FDA-approved medication to treat hospitalized COVID-19 patients (Mail Online, 2020). The positive outcome of remdesivir use will contribute to improved outcomes and reduced use of health care resources that are already scarce during this pandemic.

The immune-based therapy trials using the convalescent plasma from COVID-19 patients or SARS-CoV-2 immune globulins and the interleukin-6 inhibitors and interleukin-1 inhibitors for the treatment of COVID-19 patients is still under trial (National Institutes of Health, 2020). The current study had shown some benefit when COVID-19 convalescent plasma was used to treat individuals with severe or life-threatening symptoms of COVID-19. Patients at risk for or those with severe COVID-19 symptoms who received COVID-19 convalescent plasma within three days of diagnosis have a better chance of surviving than those who did not (Mayo Clinic, 2020b). A patient that had COVID-19 must meet specific criteria to be able to donate plasma. The criteria include no symptoms for 14 days, recovered with a negative COVID-19 test, and a high antibody level in their plasma (Mayo Clinic, 2020b). Screening for other infections and compatibility with the recipient blood group is done before plasma use. There are still some unknowns in the use of convalescent plasma, such as the duration of the immunity and the frequency or the number of times such treatment will be done as further research continuous. 
Vaccines play an important role in preventing infectious disease spread and, as such, save millions of lives globally (American Nurses Association, 2020). The development of vaccines for COVID-19 is significant for its eradication. Several vaccine developments are in progress by different pharmaceutical research and development (R\&D) units and researchers. There are different types of immunity (see Figure 9), according to the CDC (2020d), immunity against infections can be from vaccines or other sources. Approaches such as the use of vaccines made from live attenuated virus, inactivated virus, replicating and non-replicating viral vectors, recombinant protein sub-unit or virus-like particles, and researchers across the globe explore nucleic acid (DNA and mRNA) as they try to develop COVID-19 vaccines (Srivastava \& Saxena (2020). Ahmed et al. (2020) stated an imminent need to understand this new COVID-19 virus well as vaccine development progresses.

The concept of vaccination comes from the presence of an antigen from a harmful substance that produces antibodies, a protein molecule by the body's immune response process. In most standard vaccination, effectively killed or attenuated organisms, or parts of organisms is introduced as antigens into the body to produce an immune response (Tulchinsky, \& Varavikova, 2014). Scientists in China released the genetic sequence of the COVID-19 virus in January 2020, which started research around the globe for a potential vaccine, including RNA-based vaccines (U. S. National Library of Medicine, 2020).

Some pharmaceutical companies have used novel technologies to develop vaccines such as BNT162b2 and MRNA1273 using a synthetic version of the mRNA that the coronavirus uses and have received FDA's Fast Track designation and have started phase three trial (U. S. National Library of Medicine, 2020). These RNA vaccines can be constructed quickly using only the pathogen's genetic code. However, scientists have yet to determine how long the immunity 
produced by this vaccine can last (U. S. National Library of Medicine, 2020). There are some differences between the conventional vaccines and RNA vaccine, as most COVID-19 vaccine developments are RNA-based (see Table 7).

There is a great need to have an effective vaccine to combat COVID-19, but the development must come with the caution of safety. Le et al. (2020) stated that the global effort for research and development efforts for a COVID-19 vaccine in response to the pandemic is unprecedented in the aspects of speed and scale, which represents a considerable change from the traditional vaccine development pathway of five to ten years. Some of the issues to be considered include the possible mutation of the COVID-19 virus (which may make the vaccine ineffective), the side effects (which may be unknown), and the financial limitations to produce enough quantity (for the global population). Other issues to be considered include educational support to remove the myths associated with vaccination and trust in the vaccine's safety to assure that the public will take the vaccine, primarily due to the speed and rush of its development. Anderson et al. (2020) noted that one of the significant issues in this vaccine development remains the participants' availability and site for phase three trial and manufacturing enough vaccine for all when developed. All of the populations representative by age, sex, race, and ethnicity need to be tested with adequate numbers.

\section{Recommendations}

The first recommendation is to fund the research for all COVID-19 treatments. Second, establish and support strategies to increase more convalescent plasma donors. Third, create equitable access, cost, and distribution of the COVID-19 medication and vaccine. And the fourth is to mandate policies regarding vaccination to attend schools, including public and government workplaces. Effective treatments for COVID-19 require more research and development, which 
needs to be funded. These treatments could be medications, vaccines, or convalescence plasma. Collaborating with research institutes, individuals, organizations, government agencies, and federal governments to develop strategies and raise funds for this research is needed.

Professional organizations and healthcare institutions should advance their convalescent donor drive strategies to get more plasma with antibodies.

As efforts are being made to develop effective vaccines against COVID-19, measures to minimize political influences and personal gains from affecting the approval, production, and effective distribution of the vaccines when approved to the communities need to be considered. Such measures could include making the vaccines free for all when it comes out, federal funding to increases production, and a planned distribution guide to ensure fair distribution and vaccine availability. Individuals such as Bill Gates have collaborated with pharmaceutical companies to ensure safe development and availability of COVID-19 vaccines. Collaborating with more individuals and private and public organizations will help to increase vaccine availability for all. Consideration should be given to these five principle key factors: access, transparency, equity, efficacy, and safety, to ensure trust and success in COVID-19 vaccination (ANA, 2020). Global efforts should be directed towards providing vaccines to all, especially in countries that have limited resources.

\section{Testing}

Testing plays an essential role in the effort to combat the spread of COVID-19. Two types of testing (see Table 8) include a viral test called reverse transcriptase-polymerase chain reaction (RT-PCR) test through nasopharyngeal swabs and saliva to identify current infections, and antibody testing to identify evidence of the previous infection, which could be $\operatorname{IgG}, \operatorname{IgM}$, or IgA. The RT-PCR test is the gold standard for COVID-19 testing, with an average sensitivity of 
$97.2 \%$, while the serological test has an average sensitivity of $84.5 \%$ for $\operatorname{IgM}$ and $91.6 \%$ for $\operatorname{IgG}$ (Boger et al., 2020). While the CDC (2020e) recommends testing high-risk individuals as a priority, expanding access to test to the public will be very beneficial as asymptomatic patients contribute to a high level of community spread. The RT PCR-based diagnostic test takes 48 hours and more for results to be back (Younes et al., 2020), which creates delays in quarantine and other treatment decisions such as elective surgery, and bed placement in healthcare institution for inpatient admission. In reality, for many states, it takes 5-7 days for results to be available due to limited resources for timely collection, analysis, and test reporting in the laboratories.

Several studies have noted that although negative test results may be enough for low-risk individuals, additional measures should be taken to protect against the spread of COVID-19 in false-negative, asymptomatic high-risk individuals and populations (Furst, 2020; West et al., 2020; Zitek, 2020)). It is important to note that a negative test may be a false negative or that the individual is not infected at the time of the test but can still be infected. A positive test is highly suggestive of having true COVID-19. This is significant because false-negative result carries greater consequences of relaxing some individual's perspective and personal prevention strategies contributing to an increased spread.

\section{Recommendations}

The first recommendation is to fund the resources for testing and increasing the number of tests performed daily through free testing for all. The second is to increase access to COVID19 testing in the community by implementing community-testing programs. To improve health and healing, it is recommended that access to health care and health care services be expanded for all. This expansion will include access to COVID-19 testing and testing sites targeting areas 
with increased disparities. Strategies to provide free treatment, testing, and prevention for all should be firmly instituted and implemented. Such measures may include implementing a community-testing program and increasing testing sites in the community. Funding for more resources to collect, analyze, and report COVID-19 tests timely will help eliminate delays and decrease spread in the communities from asymptomatic and pre-symptomatic individuals who wait longer for their test results or may not even have access to testing.

Ritchie et al. (2020) stated that testing guides the COVID-19 pandemic, helping to understand better how the virus is spreading to respond appropriately. As testing is increased, infected individuals are identified. This helps guide interventions, and efficient allocation of resources enables proper isolation of infected individuals and improves tracking and quarantining of identified contacts. Some countries have implemented several ways to increase testing that have been helpful in their approach to slow down the spread of COVID-19. As of September 16, countries such as the United Arab Emirates and Denmark perform a high daily testing rate ( 8.56 and 7.16 , respectively) compared to the United States that performs 2.22 daily tests per thousand people (Ritchie et al., 2020). Evidence has shown that some countries or regions have slowed the spread of COVID-19 using large-scale testing and case isolation, as seen in South Korea (Cherif and Hasanov, 2020) and a Veneto community in Italy (Zingales, 2020).

Since testing is beneficial, adopting and implementing these recommendations is essential. These can be achieved through collaboration with professional organizations, community groups, and lobbying specific organizations or individuals. Some local, state and national organizations have staffed community-testing centers, as seen in some community hospitals' effort to conduct community testing in some states, but more is still needed. There is a 
great need for more individual and organizational collaboration in funding to have COVID-19 testing sites and make testing easily accessible for all with timely turn-around for results.

\section{Contact Tracing}

The CDC has recommended contact tracing as a critical strategy for preventing the continual spreading of COVID-19. Closely monitoring and examining family members can achieve early prevention and control of COVID-19 infection and social contacts of COVID-19 patients, even if they do not have any symptoms (CDC, 2020a; Pan et al., 2020). Immediate identification, self-isolation or quarantine, and monitoring of COVID-19 patients and their exposed close contacts can break the chain of disease transmission, effectively preventing the further spread of the virus. The CDC (2020a) stated that the steps of contact tracing are laborintensive and include: case investigation (identifying close contact of infected patients), contact tracing (notifying the exposed contact), contact support (providing educational information and resource support for the exposed contact), and self-quarantine (stay home and social distance for 14 days from exposure date). COVIDTracer, a new spreadsheet-based tool, allows for comparing three different strategies used for contact tracing, and the CDC developed monitoring by public health officials. This tool is very robust, with multiple stages, and requires training for effective implementation. Some other digital applications have been developed but have not been approved in some countries due to privacy concerns.

\section{Recommendations}

The recommendations include first to standardize and fund a national strategy for surveillance and contact tracing. Second, fund, support and make manual contact tracing a national strategy for infection control, including COVID-19. Contact tracing, a vital tool in the epidemiology of COVID-19, has been widely implemented in some regions, countries, and states 
to identify the contacts of infected COVID-19 patients and properly quarantine them to slow the spread. In some countries like Singapore, Taiwan, and Hong Kong, these containment measures seem to have reduced the spread of local transmission and sustain it (Cowling and Aiello, 2020). Several countries are using technology to conduct contacted tracing with promising results. Countries like Iceland implemented the Running C-19 app. Australia uses the CovidSafe app, New Zealand implemented the NZ COVID tracer app, and South Korea used multiple digital means, including phone records, to trace contacts (Dayaratna et al., 2020).

Although these digital means come with their controversy of privacy issues, these measures can be tailored to individual country's rules and regulations. Collaboration with technology sectors is recommended to discuss and plan the possibility of an effective digital method of contact tracing that will be nationally accepted considering privacy concerns. Some states have started manual contact tracing, which is labor-intensive, and with limited funds, paying for this labor remains a challenge. A situation exists where interstate travels with no uniform contact tracing by all states, creates an ineffective and inefficient contact tracing effort by the states that are doing it already. The current effort of manual contact tracing needs to be funded and supported by the federal government, making it a national strategy for infection control, including COVID-19. With the current challenge of unemployment in the country, an efficient strategy will be to hire and train individuals, especially in the rural communities, and get them in the workforce of a coordinated contact tracing system. This will provide job opportunities and provide effective use of the unemployment fund while implementing an effective strategy that has been proven to slow the spread of COVID-19.

The other two recommendations include first to implement enhanced public health intervention such as isolation centers, especially in communities with a high risk of infection 
spread. Second, encourage the private sector to develop and support voluntary isolation centers. Establishing temporary isolation centers for people with positive COVID-19 need to be implemented, especially in communities with a high risk of infection spread. With an established history of containment similarly done with infections such as tuberculosis and leprosy, countries like Iceland and South Korea used these containment measures with good outcomes (Dayaratna et al., 2020). Although interventions to mitigate the spread of COVID-19 should be implemented for all, paying particular attention to hot spot areas by identifying contact and taking extra measures to isolate or have them quarantine will be beneficial. Policymakers and legislators need to adopt this containment measure to slow down the spread of COVID-19, especially in the communities with a limited place for isolation. Lawmakers need to collaborate and lobby private, and business sectors with space currently incurring significant setbacks such as the hotel and cruise industries to provide designated space for less or no cost. Discussion with private and government insurance branches for coverage of isolation services as in other medical treatments is recommended as these measures come with a cost. These are strategies that can be kept in place and ready in future public health emergencies.

\section{Managing Stress, Mental Health, and Healthcare Access,}

Several plans have been recommended by the CDC (2020f) to manage stress as well as improve mental health and addiction services during this COVID-19 pandemic and beyond. Some of the plans include increasing the availability and easy access to mental health services, especially in the local and rural communities, providing telehealth services, and minimizing cost. Other recommendations are listed below:

- The provision and training of adequate mental health professionals and response staff to provide triage, counseling, outreach, and education during a crisis or emergency. 
- Establish and coordinate role partners such as community-based organizations in mental health services during an emergency.

- Develop templates and communication plan to ensure prompt communication of risk for adequate follow-up and risk management.

- Develop an appropriate triage system for connection and easy flow of mental health services when needed.

- Ensure an adequate plan for interpreter and translation services to accommodate the diverse community.

- Provide easily accessible and affordable mental health and addiction services within the communities.

- Train provider groups and community support workers, including school health professionals and public health nurses, in the psychosocial consequences of emergencies and disasters.

\section{Recommendations}

The recommendations are first to expand and improved access to mental health services by investing in community programs and technology. Second, allocate funds to implement the recommended plans to improve mental health and addiction services. Third, expand coverage and reimbursement for mental health services from Medicare, Medicaid, and private insurance agencies.

Meeting the demands of mental health care was a great challenge even before COVID19. More strain has been added to this aspect of wellbeing since the COVID-19 pandemic as social structures, health systems, and the economies are significantly impacted. According to the 
UN director-general, there has been a significant impact on the wellbeing and mental health of the society by the COVID-19 pandemic and recommends three critical actions:

- The use of a societal approach to protect, promote, and care for mental health patients entails the provision of widespread emergency mental health availability and development of mental health services for future psychosocial support and support of recovery from COVID-19.

- Integrate mental health into youth entrepreneurship programs in the communities

- Integrate digital technology into scalable models to deliver services and model successful interventions that have been implemented in some countries (Rahman et al., 2020).

Some examples of these actions were seen in countries like Colombia, India, and Mozambique's digital tools to manage stress, anxiety, and depression among COVID-19 response frontline workers (Rahman et al., 2020). Family and community-based preventive interventions have been used in countries like Sierra Leone. They have successfully reduced the risk of mental health problems associated with displacement, socio-economic stress, resettlement, and poor access to care (Rahman et al., 2020). Some of these interventions focus on prevention and early identification of factors that contribute to mental health issues while providing effective treatment intervention for mental health well-being.

With COVID-19 impacting communities facing health disparities and poor access to care, digital technology to deliver the needed care has proven to be an effective strategy. This delivery could be through the invention and use of digital applications that are user friendly and can connect to the electronic health record to facilitate mental health service delivery. Some of the proven ways to connect to the community and increase community programs that focus on 
mental health well-being collaborate with community organizations, investing in community entrepreneurship, and mobilizing youth champions for effective youth programs. Establishing community programs and technology innovations requires funding. Some of the ways to fund these programs can be through lobbying and collaborations with organizations, churches, and technology companies for support. Legislative support and buy-in for state and or federal funding is also needed for a wide-scale approach.

\section{Healthcare Access through Telehealth}

Telehealth has contributed much to the continuity of care for patients during this COVID19 pandemic. Telehealth is an efficient and effective way to triage and provide timely medical care to patients during this crisis moment (Lee et al., 2020). Telehealth can help maintain issues with access and continuity of care for the patients, minimize the spread of COVID-19, optimize in-person services, and provide maximum support for colleagues on the front line (Lee et al., 2020). Patients could receive care without exposing themselves or their providers since the provider uses the telephone or video. This system also helped reduce emergency room congestion for less severe cases, as in-person care is limited to the most urgent patients.

To respond to COVID-19 and appropriately provide adequate and timely care to Medicare beneficiaries during this pandemic, the Centers for Medicare and Medicaid Services (CMS, 2020) expanded access to the telehealth method of providing care and services with a full reimbursement. This expansion has helped increase patient access to the primary care provider and specialty services and reduce exposure and spread of COVID-19, especially those at high risk of complications from COVID-19. Under the 1135 waiver authority and Coronavirus Preparedness and Response Supplemental Appropriations Act, CMS expanded the telehealth 
services temporarily to allow the exchange of medical information from one site to another using electronic communications (CMS, 2020).

\section{Recommendations}

The recommendations include first to make the Medicare expansion of telehealth permanent beyond the COVID-19 public health emergency. Second, extend telehealth coverage for Medicaid and other private insurance holders. Policy barriers that limit treatment during the COVID-19 crisis, such as limited telehealth eligibility, controlled substance prescriptions restrictions, and limited access to emergency and essential healthcare services that have been modified to improve care, should be made permanent. Telehealth has contributed to increased access to healthcare services while minimizing patient and staff exposure; thereby, slowing the community spread of COVID-19. To continue to improve patient's health outcomes, the use of telehealth services needs to be made permanent.

In the present healthcare uncertainties, telehealth will benefit Medicare patients and help eliminate barriers that affect healthcare access around the globe, especially in rural areas and regions without adequate healthcare resources. Telehealth remains a possible approach to overcoming healthcare barriers existing in the world where ethnic origin, socio-economic status, and geographical locations determine community access to healthcare services (Eccles, 2012). This approach has proven successful in India's countries, even before the COVID-19 pandemic (Eccles, 2012). Lawmakers need to keep the Medicare expanded telehealth services permanent and extend the telehealth coverage to Medicaid and other private insurance groups.

\section{Safe Reopening of the Economy}

Dangers faced by emotions, fear, apathy, and selfishness may hinder the guidelines and regulations, although this is not justified. How to help develop individualized coping 
mechanisms to COVID-19 practices remains an area that needs further exploration as cities and states begin their cautious phases of reopening. Consideration for reopening of schools, businesses, bars and restaurants, recreational centers, theme parks, infrastructures, and travel, requires that specific guidelines be followed to minimize the resurgence of COVID-19. While there is an urgent need to reopen the economy, doing so in a way that will prevent the resurge of infection and a subsequent second shutdown could prevent lasting and profound damage (Stock, 2020). Everyone should uniformly practice preventive measures such as mask-wearing in public, social distance, and hand washing for public health safety.

Among the significant issues in the safe reopening of the economy is in reopening the schools, which comes with numerous school levels. The utmost controversy is that there is no set general standard when it comes to practices for school reopening, but instead, it depends on the agreement of the individual schools and local government. Tria (2020) noted that reducing the student-teacher ratio remains one of the challenges of school reopening, as schools will be faced with a lack of space for classrooms and a lack of staff to run the school. Every learning institution should plan to implement measures and policies for physical distancing, cleaning, and wearing facemasks. Some schools in different countries that reopened have recorded a resurgence in COVID-19. The inability to maintain social distancing and asymptomatic patients, coupled with the fact that some school-age children will be cared for by adults has been challenging. A standardized approach to preventive strategies is required with increased surveillance, testing, and contact tracing for the safe reopening of schools and other economic sectors. 


\section{Recommendation}

Establish a national standard for the safe reopening of schools for all education levels. Based on the evidence, when adequately implemented, preventive strategies help to minimize the spread of COVID-19 and need to be implemented and enforced uniformly in all public and private schools. The board of education in the local, state and national government and private sectors must come together and develop a uniform standard for safe school reopening with defined strategies to ensure compliance. Some countries such as Israel, France, and South Korea, issued a detailed guideline for school reopening, which addressed mask-wearing, social distancing with class size, testing, contact tracing, sports, and school cleaning. In Taiwan, the education ministry established a detailed general guideline to uniformly be implemented by all schools combining numerous strategies that included containment and mitigation practices to keep operating (Cheng et al., 2020). These include defining mask-wearing guidelines, class sizes, school cleaning requirements, temperature checks, hand hygiene, proper ventilation, contact tracing, quarantine, travel history, and modified classroom routines. Addressing safe reopening issues at both local, state, and national levels and establishing a national framework that will guide different schools as they reopen safely is needed and should be adopted.

\section{Education and Creating Awareness}

The knowledge of COVID-19 and strategies for protecting and preventing its spread is essential as it continues to evolve. Local, state, and national health departments, public health officials, providers, and other healthcare personnel should collaborate with the schools, public, and other private and public agencies to create awareness regarding COVID-19 (Ashour et al., 2020; Srivastava \& Saxena, 2020). Rural communities, especially the vulnerable populations, need to be educated on the use of PPE's, the need for social distancing, hand washing, what to do 
if infected, when to seek medical help, the importance of influenza (flu) vaccine, and other available options such as testing, contact tracing, and medical care. Myths surrounding COVID19 practices such a negative test means that one will not get COVID-19 or people wearing a mask do not need to practice social distancing are inaccurate and need to be dispelled.

The public should be educated on the proper technique for mask-wearing and proper handwashing to ensure adequate coverage of the nose and mouth, not to touch the inside of the mask, and proper disposal of masks. The public should understand that wearing a mask by everyone is more efficient in protecting everyone. The first wearer protects another, and another wearing mask protects the first wearer as it contains the virus and prevents it from spreading to one another. The public wearing a mask may become the face of a unified action to fight against the common threat of COVID-19 and reinforce the importance of social distancing measures (Javid et al., 2020). Education to explain the difference between isolation and quarantining (see Table 3) is essential to slow the spread of COVID-19. Flu vaccine awareness is much needed and advocating for all to take the flu vaccine should be the responsibility of all but more especially for the health care professionals.

\section{Recommendations}

Teach infection prevention strategies at all school levels as part of the school curriculum requirement. The global health community's goal is to decrease the spread of infectious diseases and flatten the curve's peak in any epidemic crisis. Public education regarding the various aspects of disease transmission, preventive measures, and available treatment modalities will help achieve this goal when implemented quickly. Continuous and constant reinforcements of these preventive measures are needed to reduce the resurgence of COVID-19 as schools and other private and public sectors reopens. The current surge in COVID-19 among youths is partly 
attributed to poor understanding and non-compliance to established preventive strategies. Efforts should be made towards implementing some initiatives that can continuously keep youths informed and boost compliance. A public fact sheet (see Figure 10) will help create awareness on keeping safe while dealing with COVID-19 and ways to prevent its spread. In contrast, the provider fact sheet (see Figure 11) will center on the prevention of COVID-19, treatment approach, mental health consideration, and patient education. Transparent and careful communications and awareness of the preventive measures will help promote public engagement and improve compliance.

The other recommendations include first to provide incentives for flu vaccine administration in the fee for the performance module of healthcare reimbursement. Second, implement and fund educational outreach and mobile flu vaccine clinics, especially in rural communities. Third, businesses, schools, healthcare facilities, and colleges should mandate flu vaccination. Finally, healthcare reimbursement and insurance agencies should offer discount rates if individuals or groups take influenza vaccines.

Influenza season has always been a challenging moment in infection control, with many individuals still hesitant in taking the flu vaccine. Most people have also expressed the same hesitancy for the COVID-19 vaccines that are being developed. Looking at the statistics in the past influenza season (see Table 9), it is evident that there is a great need for education and advocacy to increase the acceptance of flu vaccine for population health. COVID-19 is still evolving, and healthcare is faced with the unknown of dealing with influenza and COVID-19. The impact has been speculated to be devastating if people will not take the flu vaccines. Strategies such as massive educational outreach and mobile community flu clinics will increase understanding, access, and flu vaccination availability to the public. Initiatives that will increase 
education and provision of flu vaccines to patients, such as providing an incentive for providers that document their education and providing flu vaccines to their patients, will increase compliance similar to the strategy used with smoking cessation. Businesses, schools, healthcare facilities, and colleges should mandate flu vaccination, just like other vaccinations such as chickenpox, meningitis, and MMR. Healthcare reimbursement and insurance agencies should offer incentives to individuals and groups that received the flu vaccine in the form of reduced premium rates or reduced service fees.

Long-term policies, sustainable measures, and structural measures must extend beyond the current COVID-19 crisis. Such measures include more vital nutritional support, universal basic income, more comprehensive reentry support, and job guarantees that will improve population safety and stability during this COVID-19 crisis and beyond (The Heartland Alliance, 2020). The needs of the ethnic and racial minorities, the poor and underprivileged, and other vulnerable populations should be monitored, addressed, and protected.

\section{Dissemination Plan}

This project will be reviewed by the course professor, university peers, the DNP student preceptor, and an academic mentor before dissemination. The dissemination will start in the community and include religious organizations, department stores, schools, park district recreational centers, and colleges using flyers, fact sheets, and posters. The project will also be disseminated in the healthcare organization using PowerPoint, where the leadership teams and front-line staff will be invited to a town hall meeting. Dissemination to the local, state, and national legislators through email or online platforms will also be done at the end of the project.

Poster presentations in one of the local nursing organizations (Nigerian Illinois Nurses Association) with national affiliation will be done through Zoom and podium presentations 
during face-to-face events. Poster and podium presentations will help to reach the vast majority of people. On the national level, an abstract will be submitted to the 28th National EvidenceBased Practice Conference, University of Iowa Health Care, held on April 14 and 15, 2021. If accepted, it will display a poster presentation for viewing during the event. An abstract will also be submitted to the Illinois Society for Advanced Practice Nursing (ISAPN), American Nurses Association conference, and Sigma Theta Tau International Honor Society of Nursing, with a full project presentation in the future.

Other areas include dissemination to policymakers as well as government and private agencies through emails, journals, and other online platforms. The publication will be done through the nursing journal, such as the American Journal of Nursing, because this is one of the broad-based and most honored nursing journals that provide peer-reviewed and evidence-based articles to the vast majority of the audience. This project's full text will be disseminated through submission to the Scholarship and Open Access Repository (SOAR) and Virginia Henderson International Nursing Library for global dissemination.

\section{Conclusion}

The unprecedented threats brought by COVID-19 have led to some strategic responses by the federal, state, and local governments and communities to mitigate health and economic unrest. Covid-19 is still an evolving infection with no established medical cure yet available. Efforts to end this pandemic lie in compliance with preventive measures, the development, and availability of effective treatment, and a COVID-19 vaccine. The devastating effect of the COVID-19 pandemic has affected the global community slowing the business and economic sectors, schools, healthcare services, and individual living situations. The review of available evidence on COVID-19 revealed some preventive measures that could help prevent the spread of 
COVID-19 and minimize its impact on the global communities. Preventive measures should be widely encouraged at all levels of human operations and measured to ensure that awareness and compliance are embraced with all seriousness. The fact sheets were used to disseminate the identified practices to help reduce the spread of COVID-19. A global approach to preventive measures, treatment, and vaccines is needed to deal with the COVID-19 pandemic. 


\section{References}

American Nurses Association. (2020). COVID-19 vaccines.

https://www.nursingworld.org/practice-policy/work-environment/health-safety/disasterpreparedness/coronavirus/what-you-need-to-know/covid-19-vaccines/

Ahmed, S., Quadeer, A., \& McKay, M. (2020). Preliminary identification of potential vaccine targets for the COVID-19 coronavirus (SARS-CoV-2) based on SARS-CoV immunological studies. Viruses, 12(3), 254-258. https://doi.org/10.3390/v12030254

Al-Sadeq, D. W., \& Nasrallah, G. K. (2020). The incidence of the novel coronavirus SARSCoV-2 among asymptomatic patients: A systematic review. International Journal of Infectious Disease, 98, 372-380. https://doi.org/10.1016/j.ijid.2020.06.098

Anderson, R. M., Heesterbeek, H., Klinkenberg, D., \& Hollingsworth, T. D. (2020). How will country-based mitigation measures influence the course of the COVID-19 epidemic? The Lancet. https://doi.org/10.1016/S0140-6736(20)30567-5

Ashour, M., Elkhatib, F., Rahman, M., \& Elshabrawy, A. (2020). Insights into the recent 2019 novel coronavirus (SARS-CoV-2) in light of past human coronavirus outbreaks. Pathogens 9(3). https://doi.org/10.3390/pathogens9030186

Bahl, P., Doolan, C., de Silva, C., Chughtai, A. A., Bourouiba, L., \& MacIntyre, C. R. (2020). Airborne or droplet precautions for health workers treating coronavirus disease 2019. The Journal of Infectious Diseases, 189. https://doi.org/10.1093/infdis/jiaa189

Bajwah, S., Wilcock, A., Towers, R., Costantini, M., Bausewein, C., Simon, S. T., Bendstrup, E., Prentice, W., Johnson, M. J., Currow, D. C., Kreuter, M., Wells, A. U., Birring, S. S., Edmonds, P., \& Higginson, I. J. (2020). Managing the supportive care needs of those 
affected by COVID-19. European Respiratory Journal, 55(4).

https://doi.org/10.1183/13993003.00815-2020

Beigel, J. H., Tomashek, K. M., Dodd, L. E., Mehta, A. K., Zingman, B. S., Kalil, A. C., Hohmann, E., Chu, H. Y., Luetkemeyer, A., Kline, S., Lopez de Castilla, D., Finberg, R. W., Dierberg, K., Tapson, V., Hsieh, L., Patterson, T. F., Paredes, R., Sweeney, D. A., Short, W. R., ... Lane, C. (2020). Remdesivir for the Treatment of Covid-19-Final Report. The New England Journal of Medicine. https://www.nejm.org/doi/full/10.1056/NEJMoa2007764?query=featured_home\#article_ citing_articles

Boger, B., Fachi, M. M., Vilhena, R. O., Cobre, A. F., Tonin, F. S., \& Pontarolo, R. (2020). Systematic review with meta-analysis of the accuracy of diagnostic tests for COVID-19. American Journal of Infection Control. https://doi.org/10.1016/j.ajic.2020.07.011

Canadian Centre for Occupational Health and Safety. (2020). Hand washing: Reducing the risk of common infections. https://www.ccohs.ca/oshanswers/diseases/washing_hands.html

Center for Disease Control and Prevention. (2015). CDC's policy analytical framework https://www.cdc.gov/policy/analysis/process/analysis.html

Center for Disease Control and Prevention. (2020a). Contact tracing-CDC's role and approach. https://www.cdc.gov/coronavirus/2019-ncov/downloads/php/contact-tracing-CDC-roleand-approach.pdf

Center for Disease Control and Prevention. (2020b). Coronavirus disease 2019 (COVID-19): Symptoms of coronavirus. https://www.cdc.gov/coronavirus/2019ncov/symptoms-testing/symptoms.html

Center for Disease Control and Prevention. (2020c). COVID-19 in racial and ethnic minority 
groups. https://www.cdc.gov/coronavirus/2019-ncov/need-extra-precautions/racialethnic-minorities.html

Center for Disease Control and Prevention. (2020d). How to protect yourself and others. https://www.cdc.gov/coronavirus/2019-ncov/prevent-getting-sick/prevention.html Center for Disease Control and Prevention. (2020e). Evaluating and Testing Persons for Coronavirus disease 2019 (COVID-19). https://www.cdc.gov/coronavirus/2019$\mathrm{nCoV/hcp/clinical-criteria.html}$

Center for Disease Control and Prevention. (2020f). Mental health and coping during COVID19. https://www.cdc.gov/coronavirus/2019-ncov/daily-life-coping/managing-stressanxiety.

Centers for Medicare and Medicaid Services. (2020). Telehealth benefits in Medicare are a lifeline for patients during coronavirus outbreak. https://www.cms.gov/newsroom/pressreleases/telehealth-benefits-medicare-are-lifeline-patients-during-coronavirus-outbreak

Chan, B. T. Y. (2020). Addressing conflicting views on wearing of facemask by the public to combat COVID-19: Experiences from the East Asia region. Journal of Global Health Reports, 4. https://doi.org/10.29392/001c.13066

Chen, T., Wu, D., Chen, H., Yan, W.,Yang, D., Chen, G.,Ma, K., Xu, D., Yu, H., Wang, H., Wang, T., Guo, W., Chen, J., Ding, C., Zhang, X., Huang, J., Han, M., Li, S., Luo, X., ..., Ning, Q. (2020). Clinical characteristics of 113 deceased patients with coronavirus disease 2019. BMJ. 368, M 1295. https://doi.org/10.1136/bmj.m1091

Cheng, S., Wang, J., Shen, A. C., \& Chang, S. (2020). How to safely reopen colleges and universities during COVID-19: Experience from Taiwan. Annals of Internal Medicine. https://doi.org/10.7326/M20-2927 
Cherif, R., \& Hasanov, F. (2020). Universal testing: An overlooked Covid-19 policy response. https://voxeu.org/article/universal-testing-overlooked-covid-19-policy-response

Cowling, B. J., \& Aiello, A. E. (2020). Public health measures to slow community spread of coronavirus disease 2019. The Journal of Infectious Diseases, 221(11), 1749-1751, https://doi.org/10.1093/infdis/jiaa123

Dayaratna, K., Tyrell, P., \& Vanderplas, A. (2020). A comparative analysis of policy approaches to COVID-19 around the world, with recommendations for U.S. lawmakers. The Heritage Foundation. https://www.heritage.org/public-health/report/comparativeanalysis-policy-approaches-covid-19-around-the-world

de Lucena, T. M. C., da Silva Santos, A. F., de Lima, B. R., de Albuquerque Borborema, M. E., \& de Azevedo Silva, J., (2020). Mechanism of inflammatory response in associated comorbidities in COVID-19. Research and Reviews, 14(4), 597-600. https://doi.org/10.1016/j.dsx.2020.05.025

Desson, Z., Lambertz, L., Peters, J., Falkenbach, M., \& Kauer, L. (2020). Europe's Covid-19 outliers: German, Austrian and Swiss policy responses during the early stages of the 2020 pandemic. https://doi.org/10.1016/j.hlpt.2020.09.003

Dong, Y., Mo, X., Hu, Y., Qi, X., Jiang, F., Jiang, Z., \& Tong, S. (2020). Epidemiology of COVID-19 among children in China. Journal of the American Academy of Pediatrics, 145(6). doi: https://doi.org/10.1542/peds.2020-0702

Eccles, N. (2012). Telemedicine in developing countries: Challenges and successes. Global Health Review. http://www.hcs.harvard.edu/hghr/print/spring-2011/telemedicinedeveloping/ 
Emanuel, E. J., Persad, G., Upshur, R., Thome, B., Parker, M., Glickman, A., Zhang, C., Boyle, C., Smith, M., \& Phillips, J. P. (2020). Fair allocation of scarce medical resources in the time of COVID-19. The New England Journal of Medicine, 382, 2049-2055. https://www.nejm.org/doi/10.1056/NEJMsb2005114

Equal Justice Initiative. (2020). COVID-19's impact on people in prison. https://eji.org/news/covid-19s-impact-on-people-in-prison/

Environmental protection Agency. (2020). List N: Disinfectants for Coronavirus (COVID-19). https://www.epa.gov/pesticide-registration/list-n-disinfectants-coronavirus-covid-19

Fogarty, H., Townsend, L., Cheallaigh, C. N., Bergin, C., Martin-Loeches, I., Browne, P., Bacon, C. L., Gaule, R., Gillett, A., Byrne, M., Ryan, K., O’Connell, N., O’Sullivan, J. M., Conlon, N., \& O'Donnell, J. S. (2020). More on COVID-19 coagulopathy in Caucasian patients. British Journal of Haematology, 189(6), 1060-1061. https://doi.org/10.1111/bjh.16791

Food and Drug Administration. (2020). Coronavirus (COVID-19 update: FDA authorizes first diagnostic test using at-home collection of saliva specimens. https://www.fda.gov/newsevents/press-announcements/coronavirus-covid-19-update-fda-authorizes-firstdiagnostic-test-using-home-collection-saliva

Furst, J. (2020). False-negative COVID-19 test results may lead to false sense of security. https://newsnetwork.mayoclinic.org/discussion/false-negative-covid-19-test-results-maylead-to-false-sense-of-security/

Gregg, J., Miller, J., \& Tennant, K. F. (2018). Nurse policy entrepreneurship in a rural community: A multiple streams framework approach. Online Journal of Issues in Nursing, 23(3), 6. https://doi.org/10.3912/OJIN.Vol23No03PPT63 
Heartland Alliance. (2020). COVID-19 policy recommendation. https://www.heartlandalliance.org/coronavirus-covid-19/policyrecs

Hopkins Medicine. (n. d.). Johns Hopkins nursing evidence-based practice: Evidence level and quality guide. https://www.hopkinsmedicine.org/evidence-based practice/_docs/appendix_c_evidence_level_quality_guide.pdf

Huang, P. (2020). We still don't fully understand the label 'asymptomatic'. https:/www.npr.org/sections/goatsandsoda/2020/06/23/864536258/we-still-dont-fullyunderstand-the-label-asymptomatic

Illinois Department of Public Health. (2020). About COVID-19. http://dph.illinois.gov/topicsservices/diseases-and-conditions/diseases-a-z-list/coronavirus/symptoms-treatment

Javid, B., Weekes, M. P., \& Matheson, N. J. (2020). COVID-19: Should the public wear face masks? BMJ, 369. https://doi.org/10.1136/bmj.m1442

Johns Hopkins Medicine. (2020). Coronavirus (COVID-19) information update. https://www.hopkinsmedicine.org/coronavirus/health-articles.html

Kandel, N., Chungong, S., Omaar, A., \& Xing, J. (2020). Health security capacities in the context of COVID-19 outbreak: An analysis of international health regulations annual report data from 182 countries. Lancet. 395(10229),1047-1053.

https://doi.org/10.1016/S0140-6736 (20)30553-5

Lai, C., Wang, C., \& Hsueh, P. (2020). Co-infections among patients with COVID-19: The need for combination therapy with non-anti-SARS-C0V-2 agents. Journal of Microbiology, Immunology and Infection. https://doi.org/10.1016/j.jmii.2020.05.013 
Landa, N., Mendieta-Eckert, M., Fonda-Pascual, P., \& Aguirre, T. (2020). Chilblain-like lesions on feet and hands during the COVID-19 Pandemic. International journal of dermatology, 59(6), 739-743. https://doi.org/10.1111/ijd.14937

Le, T. T., Andreadakis, Z., Kumar, A., Roman, R. G., Tollefsen, S., Saville, M., \& Mayhew, S. (2020). The COVID-19 vaccine development landscape. News \& Analysis, 19, 305-306. https://doi.org/10.1038/d41573-020-00073-5

Lee, H. Y. (2020). Tech experts helped make Taiwan's mask rationing system a success. Focus Taiwan. https://focustaiwan.tw/society/202002280019.

Lee, I., Kovarik, C., Tejasvi, T., Pizarro, M., \& Lipoff, J. B. (2020). Telehealth: Helping your patients and practice survive and thrive during the COVID-19 crisis with rapid quality implementation. Journal of the American Academy of Dermatology, 82(5), 1213-1214. https://doi.org/10.1016/j.jaad.2020.03.052

Levin, M. (2020). Childhood multisystem inflammatory syndrome: A new challenge in pandemic. The New England Journal of Medicine. 383-395. https://www.nejm.org/doi/full/10.1056/NEJMe2023158

Lodigiani, C., Lapichino, G., Carenzo, L., Cecconi, M., Ferrazzi, P., Sebastian, T., Kucher, N., Studt, J., Sacco, C., Alexia, B., Sandri, M., \& Barco, S. (2020). Venous and arterial thromboembolic complications in COVID-19 patients admitted to an academic hospital in Milan, Italy. Thrombosis Research, 191, 9-14. https://doi.org/10.1016/j.thromres.2020.04.024

Mail Online. (2020). Gilead's remdesivir gets FULL FDA approval as a treatment for hospitalized coronavirus patients. https://www.dailymail.co.uk/health/article8869893/FDA-approves-Gileads-remdesivir-treatment-coronavirus-patients.html 
Mayo Clinic. (2020a). Coronavirus disease 2019 (COVID-19).

https://www.mayoclinic.org/diseases-conditions/coronavirus/symptoms-causes/syc20479963

Mayo Clinic. (2020b). Expanded Access to Convalescent Plasma for the Treatment of Patients with COVID-19 protocol. https://www.uscovidplasma.org/?_ga=2.175339042. 1679547164.1591383761-342035009.1583506745

Mick, P., \& Murphy, R. (2020). Aerosol-generating otolaryngology procedures and the need for enhanced PPE during the COVID-19 pandemic. Journal of Otolaryngology - Head and Neck Surgery, 49(29). https://doi.org/10.1186/s40463-020-00424-7

Morawska, L., \& Cao, J. (2020). Airborne transmission of SARS-CoV-2: The world should face the reality. Environment International, 139, 105730. https://doi.org/10.1016/j.envint.2020.105730

National Institutes of Health. (2020). COVID-19 treatment guideline. https://www.covid19treatmentguidelines.nih.gov/whats-new/

Nicola, M., Alsafi, Z., Sohrabi, C., Kerwan, A., Al-Jabir, A., Losifidis, C., Agha, M., \& Agha, R. (2020). The socio-economic implications of the coronavirus pandemic (COVID-19): A review. International Journal of Surgery, 78, 185-193. https://doi.org/10.1016/j.ijsu.2020.04.018

Osborn, K. (2020). Use of Personal Protective Equipment (PPE) for Massage Therapists. www.abmp.com/back-to-practice.

Pan, X., Chen, D., Xia, Y., Wu, X., Li, T., Ou, X., Zhou, L., \& Liu, J. (2020). Asymptomatic cases in a family cluster with SARS-CoV-2 infection. The Lancet. Infectious diseases, 20(4), 410-411. https://doi.org/10.1016/S1473-3099(20)30114-6 
Rahman, A., Naslund, J., Betancourt, T., Black, C., Bhan, A., Byansi, W., Chen, H., Gaynes, B., Restrepo, C., Gouveia, L., Hamdani, S., Marsch, L., Petersen, I., Bahar, O., ShieldsZeeman, L., Ssewamala, F., \& Wainberg, M. (2020). The NIMH global mental health research community and COVID-19. The Lancet Psychiatry, 7(10), 834-836. https://doi.org/10.1016/S2215-0366 (20)30347-3

Rahhal, N., \& Dyer, C. (2020). How America was hit with COVID-19 from two continents. https://www.dailymail.co.uk/health/article-8206625/America-hit-COVID-19-twocontinents-studies-suggest.html

Ritchie, H., Ortiz-Ospina, E., Beltekian, D., Mathieu, E., Hasell, J., Macdonald, B., Giattino, C., \& Roser, M. (2020). Statistics and research: Coronavirus (COVID-19) testing. https://ourworldindata.org/coronavirus-testing\#canada

Rizk, J. G., Kalantar-Zadeh, K., Mehra, M. R., Lavie, C. J., Rizk, Y., \& Forthal, D. N. (2020). Pharmaco-Immunomodulatory Therapy in COVID-19. Drugs 80, 1267-1292. https://doi.org/10.1007/s40265-020-01367-z

Roche, J. A., \& Roche, R. (2020). A hypothesized role for dysregulated bradykinin signaling in COVID-19 respiratory complications. The Journal of the Federation of American Societies for Experimental Biology, 34(6), 7265-7269. https://doi.org/10.1096/fj.202000967

Rudnicka, L., Gupta, M., Kassir, M., Jafferany, M., Lotti, T., \& Sadoughifar, R. (2020). Priorities for global health community in COVID-19 pandemic. Researchgate. 1-6 https://doi.org/10.1111/dth.13361

Stock, J. S. (2020). Reopening the coronavirus-closed economy. https://www.brookings.edu/wpcontent/uploads/2020/05/WP60-Stock_final.pdf 
Srivastava, N., \& Saxena, S. (2020). Prevention and control strategies for SARS-CoV-2

Infection. Coronavirus Disease 2019 (COVID-19). Epidemiology, Pathogenesis, Diagnosis, and Therapeutics, 127-140. https://doi.org/10.1007/978-981-15-4814-7_11

Song, Z., Guiriato, M., Lillehaugen, T., Altman, W., Horn, D. M., Phillips, R. S., Barnett, K. G., Bitton, A., Edgman-Levitan, S., Choi, E., Hattis, P., McKee, D., \& Auerbach, D. (2020). Economic and clinical impact of COVID-19 on provider practices in Massachusetts. NEJM Catalyst. https://catalyst.nejm.org/doi/full/10.1056/CAT.20.0441

Thachil, J. (2020). The versatile heparin in COVID-19. Journal of Thrombosis and Haemostasis, 18(5), 1020-1022. https://doi.org/10.1111/jth.14821

The Harvard Gazette. (2020). National and world affair. https://news.harvard.edu/gazette/ story/2020/05/the-impact-of-covid-19-on-native-american-communities/

Tria, J. Z. (2020). The COVID-19 pandemic through the lens of education in the Philippines: The new normal. International Journal of Pedagogical Development and Lifelong Learning, 1(1), ep2001. https://doi.org/10.30935/ijpdll/8311

Tulchinsky, T. H., \& Varavikova, E. A. (2014). Communicable Diseases. The New Public Health, 149-236. https://doi.org/10.1016/B978-0-12-415766-8.00004-5

U. S. National Library of Medicine. (2020). A trial investigating the safety and effects of four BNT162 vaccines against COVID-2019 in healthy adults. https://clinicaltrials.gov/ct2/show/NCT04380701

Van de Veerdonk, F., Netea, M., van Deuren, M., van der Meer, J., de Mast, Q., Bruggemann, R., \& van der Hoeven, H. (2020). Kallikrein-kinin blockade in patients with COVID-19 to prevent acute respiratory distress syndrome. eLife, 9, e57555. https://doi.org/10.7554/eLife.57555 
Viner, R. M., \& Whittaker, E. (2020). Kawasaki-like disease: Emerging complication during the COVID-19 pandemic. The Lancet, 395. https://doi.org/10.1016/ S0140-6736(20)31129-6

Viner, R. M., Russell, S. J., Croker, H., Packer, J., Ward, J., Stansfield, C., Mytton, O., Bonell, C., \& Booy, R. (2020). School closure and management practices during coronavirus outbreaks including COVID-19: A rapid systematic review. The Lancet Child \& Adolescent Health, 4(5), 397-404. https://doi.org/10.1016/S2352-4642(20)30095-X

Vivanti, A. J., Vauloup-Fellous, C., Prevot, S., Zupan, V., Suffee, C., Do Cao, J., Benachi, A., \& De Luca, D. (2020). Transplacental transmission of SARS-CoV-2 infection. Nature Communications, 11, 3572. https://doi.org/10.1038/s41467-020-17436-6

Wang, X., Zhou, Z., Zhang, J., Zhu, F., Tang, Y., \& Shen, X. (2020). A case of 2019 Novel Coronavirus in a pregnant woman. Clinical Infectious Disease, 71(15), 844-846. https://doi.org/10.1093/cid/ciaa200

Walt, G., Shiffman, J., Schneider, H., Murray, S. F., Brugha, R., \& Gilson, L. (2008). 'Doing' health policy analysis: Methodological and conceptual reflections and challenges, Health Policy and Planning, 23(5), 308-317. https://doi.org/10.1093/heapol/czn024

World Health Organization. (2020a). Advice on the use of masks in the context of COVID-19: Interim guidance. WHO-2019-nCov-IPC_Masks-2020.4-eng.pdf

World Health Organization. (2020b). Coronavirus disease (COVID-19: Advice for the public https://www.who.int/emergencies/diseases/novel-coronavirus-2019/advice-for-public World Health Organization. (2020c). Coronavirus: Overview. https://www.who.int/healthtopics/coronavirus\#tab=tab_1 
World Health Organization. (2020d). Events as they happen.

https://www.who.int/emergencies/diseases/novel-coronavirus-2019/events-as-theyhappen

World Health Organization. (2020e). World Health Organization coronavirus disease (COVID19) dashboard. https://covid19.who.int/?gclid=CjwKCAjwk6P2BRAIEiwAfVJ0r

West, C. P., Montori, V. M., \& Sampathkumar, P. (2020). COVID-19 testing: The threat of false-negative results. Mayo Clinic Proceedings. https//doi.org/10.1016/j.mayocp.2020.04.004.

Xing, Q., Li, G., \& Xing, Y. (2020). Precautions are needed for COVID-19 patients with coinfection of common respiratory pathogens. Preprint from medRxiv. https://doi.org/10.1101/2020.02.29.20027698PPR: PPR115450

Younes, N., Al-Sadeq, D. W., Al-Jighefee, H., Younes, S., Al-Jamal, O., Daas, H. I., Yassine, H. M., \& Nasrallah, G. K. (2020). Challenges in laboratory diagnosis of the novel coronavirus SARS-CoV-2. Viruses, 12(6), 582. https://doi.org/10.3390/v12060582

Zeng, L., Xia, S., Yuan, W., Yan, K., Xiao, F., Shao, J., \& Zhou, W. (2020). Neonatal earlyonset infection with SARS-CoV-2 in 33 neonates born to mothers with COVID-19 in Wuhan, China. JAMA Pediatrics, 174(7), 722-725. doi:10.1001/jamapediatrics.2020.0878

Zhang, W., Zhao, Y., Zhang, F., Wang, Q., Li, T., Liu, Z., Wang, J., Qin, Y., Zhang, X., Yan, X., Zeng, X., \& Zhang, S. (2020). The use of anti-inflammatory drugs in the treatment of people with severe coronavirus disease 2019 (COVID-19): The Perspectives of clinical immunologists from China. Clinical Immunology, 214. https://doi.org/10.1016/j.clim.2020.108393 
Zingales, L. (2020). Why mass testing is crucial: The US should study the Veneto Model to fight Covid-19. https://promarket.org/2020/03/17/why-mass-testing-is-crucial-the-us-shouldstudy-the-veneto-model-to-fight-covid-19/

Zitek, T. (2020). The Appropriate Use of Testing for COVID-19. The Western Journal of Emergency Medicine, 21(3), 470-472. https://doi.org/10.5811/westjem.2020.4.47370 
Table 1.

Some COVID-19 Signs and Symptoms, and Complications

\begin{tabular}{ll}
\hline Signs and Symptoms & Complications \\
\hline Fever of $>100.4 \mathrm{~F}$ & Pneumonia \\
& Pulmonary edema, Acute respiratory failure \\
Dry or productive Cough & Elevated liver enzymes causing acute liver \\
Shortness of breath, Wheezing, Hypoxia & Acute respiratory distress syndrome \\
Chest distress, dysrhythmia & Acute kidney injury \\
Myalgia (body aches) & Acute coronary syndrome with elevated troponin \\
Nasal congestion and or rhinorrhea & Heart failure \\
Anosmia (loss of smell) & Myocarditis and Myocardial injury \\
Ageusia (loss of taste) & Arterial and venous thromboembolism \\
Loss of appetite & Prothrombotic coagulopathy \\
Sore throat, pharyngeal pain & Macrophage activation syndrome \\
Nausea, Vomiting, Diarrhea & Cytokine storm \\
Abdominal pain & Shock and multi-organ dysfunction \\
Lassitude or weakness, fatigue & Impaired consciousness \\
Reduced alertness and or mobility & Acute cerebrovascular disease \\
Headache, Delirium, confusion & Cutaneous manifestations of popular and reddish \\
& lesion like chilblains seen on the toes (COVID \\
toes), soles, fingers or heel. \\
In children: Kawasaki-like disease & Lingering memory issues, fatigue, and \\
symptoms: non-purulent conjunctivitis, & debilitating pain for some patient that have \\
polymorphic rash, mucosal changes, and & recovered from COVID-19 has been reported. \\
swollen extremities & \\
-Multisystem inflammatory syndrome in & \\
children (MIS-C) & \\
\hline
\end{tabular}


Table 2.

John Hopkins Evidence Level

Johns Hopkins Nursing Evidence-Based Practice
Appendix C: Evidence Level and Quality Guide

\begin{tabular}{|c|c|}
\hline $\begin{array}{l}\text { Level V } \\
\text { Based on experiential and non-research evidence } \\
\text { Includes: } \\
\text { - Literature reviews } \\
\text { - Quality improvement, program or financial evaluation } \\
\text { - Case reports } \\
\text { - Opinion of nationally recognized experts(s) based on } \\
\text { experiential evidence }\end{array}$ & 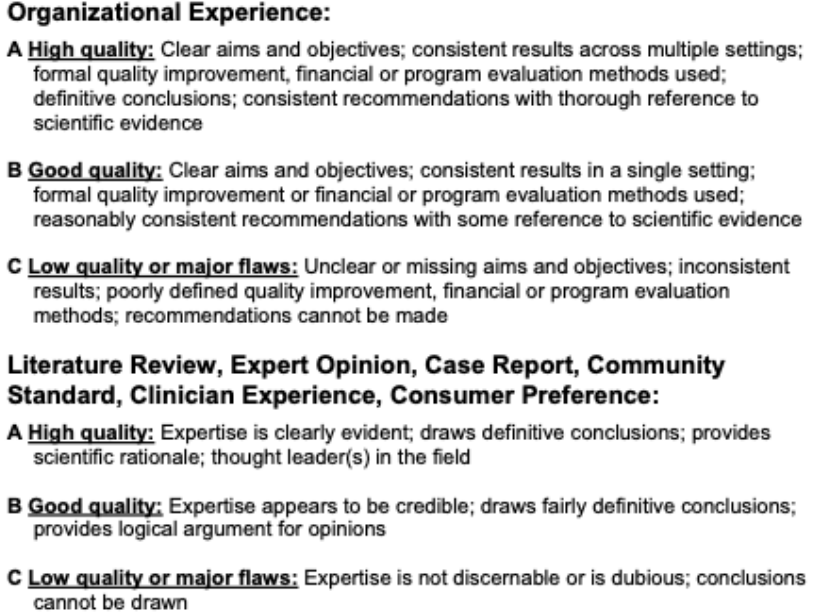 \\
\hline
\end{tabular}

Johns Hopkins Nursing Evidence-Based Practice Appendix C: Evidence Level and Quality Guide

\begin{tabular}{|c|c|}
\hline Evidence Levels & Quality Guides \\
\hline $\begin{array}{l}\text { Level I } \\
\text { Experimental study, randomized controlled trial (RCT) } \\
\text { Systematic review of RCTs, with or without meta-analysis }\end{array}$ & \multirow{3}{*}{$\begin{array}{l}\text { A High quality: Consistent, generalizable results; sufficient sample size for the study } \\
\text { design; adequate control; definitive conclusions; consistent recommendations based } \\
\text { on comprehensive literature review that includes thorough reference to scientific } \\
\text { evidence } \\
\text { B Good quality: Reasonably consistent results; sufficient sample size for the study } \\
\text { design; some control, fairly definitive conclusions; reasonably consistent } \\
\text { recommendations based on fairly comprehensive literature review that includes } \\
\text { some reference to scientific evidence } \\
\text { C Low quality or major flaws: Little evidence with inconsistent results; insufficient } \\
\text { sample size for the study design; conclusions cannot be drawn }\end{array}$} \\
\hline $\begin{array}{l}\text { Level II } \\
\text { Quasi-experimental study } \\
\text { Systematic review of a combination of RCTs and quasi- } \\
\text { experimental, or quasi-experimental studies only, with or without } \\
\text { meta-analysis }\end{array}$ & \\
\hline $\begin{array}{l}\text { Level III } \\
\text { Non-experimental study } \\
\text { Systematic review of a combination of RCTs, quasi-experimental } \\
\text { and non-experimental studies, or non-experimental studies only, } \\
\text { with or without meta-analysis } \\
\text { Qualitative study or systematic review with or without a meta- } \\
\text { synthesis }\end{array}$ & \\
\hline
\end{tabular}


Table 3.

COVID-19 Quarantine vs Isolation

\begin{tabular}{ll}
\hline Isolation & Quarantine \\
\hline Symptomatic and positive asymptomatic & Individuals who are in close contact \\
individuals are kept away from others even in & (exposed) with COVID-19 positive individual \\
their homes. & is kept away from others \\
& Exposure means: Being within six feet of \\
& contact for 15 minutes or more, direct contact \\
& without proper PPE as in providing care, \\
& sharing eating or drinking utensils, or being \\
& sneezed or coughed at or exposed to COVID- \\
& 19 droplets.
\end{tabular}

Stay home for 10 days from date of onset of symptoms, and 24 hours fever free without fever reducing agents, and with improved symptoms.

Stay home for 10 days from the date of your last positive test.

In a multi-living situation, stay away from others in a designated "sick room" with a separate bathroom if possible.
Stay home for 14 days from the date of your last exposure.

(Center for Disease Control and Prevention, 2020d; Srivastava, \& Saxena, 2020) 
Table 4.

Mask Overview

\begin{tabular}{ll}
\hline Type of Mask & Description \\
\hline N95 & $\begin{array}{l}\text { A respirator mask that offers more protection than a surgical mask. } \\
\text { It can filter out both large and small particles when the wearer inhales. } \\
\text { Designed to block 95\% of very small particles }\end{array}$ \\
& $\begin{array}{l}\text { Some N95 masks have valves that make them easier to breathe through. } \\
\text { With this type of mask, unfiltered air is released when the wearer exhales. }\end{array}$ \\
& -Fit testing recommended for the proper size. \\
Surgical mask & $\begin{array}{l}\text { A loose-fitting disposable mask that protects the wearer's nose and mouth. } \\
\text { Filters out large particles in the air such as droplets, splashes, and sprays } \\
\text { that may contain germs }\end{array}$ \\
& $\begin{array}{l}\text { To cover the wearer's mouth and nose but not certain if it offers protection } \\
\text { Cloth mask }\end{array}$ \\
& Filters dust particles and mostly for occupational work \\
\hline
\end{tabular}

(Osborn, 2020) 
Table 5.

Airborne and Droplet Isolation

\begin{tabular}{ll}
\hline Airborne Precaution & Droplet Precaution \\
\hline $\begin{array}{l}\text { Used when the transmission is by inhaling } \\
\text { viral particles floating freely in the air or } \\
\text { aerosol. }\end{array}$ & $\begin{array}{l}\text { Used when the transmission is by contact } \\
\text { with droplet particles. }\end{array}$ \\
$\begin{array}{l}\text { Aerosols: Tiny particles that can be } \\
\text { suspended in the air and float for a longer } \\
\text { period, leading to airborne transmission. }\end{array}$ & $\begin{array}{l}\text { Droplets: Mucous or saliva particles large and } \\
\text { heavier than air are expelled, falling towards } \\
\text { the ground and immediately come in contact } \\
\text { with another person's mouth, nose, the } \\
\text { mucous membrane of eyes, or on surfaces. }\end{array}$ \\
$\begin{array}{l}\text { Airborne: Virus droplet particles that are } \\
\text { small enough to float in the air for a longer } \\
\text { period. }\end{array}$ & $\begin{array}{l}\text { Precautions include wearing a surgical mask, } \\
\text { eye covering or face shield, gloves, and gown, } \\
\text { and isolating the patient in a room. }\end{array}$ \\
$\begin{array}{l}\text { Because the COVID-19 viral particles } \\
\text { expelled can be aerosol or large enough to be } \\
\text { droplets, precaution include wearing an N95 } \\
\text { or higher-level respirator, eye covering or } \\
\text { face shield, gloves, and gown, and isolating } \\
\text { the patient in a negative } \\
\text { pressure airborne infection isolation room. }\end{array}$ & \\
\hline
\end{tabular}

(Bahl et al., 2020; Center for Disease Control and Prevention, 2020d) 
Table 6.

\section{COVID-19 Supportive Treatment}

\begin{tabular}{|c|c|}
\hline Problem & Supportive treatment \\
\hline Fever & Use antipyretics alongside other fever-reducing measures. \\
\hline Dry cough & $\begin{array}{l}\text { Provide comfort measures to relieve cough may be needed such as small } \\
\text { sips of water, although relatively low dose opioids such as oral morphine } \\
\text { may help reduce cough alongside treatment for breathlessness }\end{array}$ \\
\hline $\begin{array}{l}\text { Thrombotic event } \\
\text { prophylaxis }\end{array}$ & $\begin{array}{l}\text { Administer low-molecular-weight heparin in the early phase of COVID- } \\
19 \text { treatment for a positive effect on thrombosis prevention as well as } \\
\text { reducing systematic and pulmonary inflammation. }\end{array}$ \\
\hline $\begin{array}{l}\text { Bacterial Co- } \\
\text { infection }\end{array}$ & $\begin{array}{l}\text { Use antibiotics but in a situation where bacterial co-infection cannot be } \\
\text { ruled out in COVID-19 patients, the use of empirical antibiotics was } \\
\text { recommended for mild cases and a broad-spectrum antibiotic coverage is } \\
\text { suggested for severe cases. }\end{array}$ \\
\hline Inflammation & $\begin{array}{l}\text { Corticosteroids (prednisone, methylprednisolone) and Dexamethasone } \\
\text { are potent anti-inflammatory drugs that have been used. }\end{array}$ \\
\hline Hypoxia & $\begin{array}{l}\text { Oxygen therapy is given through a nasal cannula to correct hypoxemia } \\
\text { and improve oxygenation. Some severe cases may require a non- } \\
\text { rebreather mask, a Bi-pap machine, or possibly ventilator support. }\end{array}$ \\
\hline Anxiety & $\begin{array}{l}\text { Anxiety-related to fear, social and family isolation, and breathlessness } \\
\text { may be present in some patients, studies have shown that non- } \\
\text { pharmacological methods such as breathing exercise and relaxation } \\
\text { therapy are helpful in mild cases. }\end{array}$ \\
\hline
\end{tabular}

(Bajwah et al., 2020; Lai et al., 2020; Rizk et al., 2020; Thachil, 2020) 
Table 7.

Comparison of RNA and Some Standard Vaccines

\begin{tabular}{ll}
\hline RNA Based Vaccine & Some Standard Vaccine \\
\hline Synthetic & Inactivated pathogen \\
Uses pathogen's genetic code & Uses the weakened form of the virus \\
Quicker to construct & Takes longer to develop \\
\hline
\end{tabular}

(U. S. National Library of Medicine, 2020) 
Table 8.

COVID-19 Testing

Viral test- Reverse transcription-polymerase chain reaction (RT-PCR).

Nasal Swab and Saliva

Sputum specimen sensitivity from

nasopharyngeal swab remains at an average of $97.2 \%$. Result turn around takes up to 48 hours and more.

Identifies the RNA of COVID-19 virus

The RT-PCR-based test is the gold standard for COVID-19 diagnostic

More prone to deterioration during sample collection, preparation, transport, storage, and testing compared to serological testing. Negative result does not mean the absence of COVID-19 but simply mean that there is a probability that the individual is not infected at the time of sample collection and can still be infected
Serological tests

(Binding antibody detection test)

Blood/Saliva: Laboratory-enzyme immunoassays (EIA) and rapid, point of care (POC) tests (blood which can be by finger stick or saliva). Can be collected easily from the blood draw.

Detects antibodies IgG, IgM, and IgA. IgG- remain detectable for months or years. The average sensitivity of $91.6 \%$.

IgM- for recent infection as it may disappear weeks to months following infection. The average sensitivity is $84.5 \%$.

IgA- important for mucosal immunity and can be detected in mucous secretions like saliva in addition to blood

Not be enough to diagnose COVID-19, combine with molecular techniques for a valuable diagnostic result.

Can detect past infection providing better information on disease prevalence in the population.

Fewer variations compared to nasopharyngeal specimens because antibodies are usually homogeneously dispersed in the blood.

Slow antibody response to SARS-CoV-2 virus, as they may not be detectable until three days from symptom onset or at least 7-10 days after infection

Not designed to detect individuals in the early stages of COVID-19 infection.

Unreliable for the detection of acutely infected individuals as less than $40 \%$ of infected individuals are seropositive $(\operatorname{IgM} / \operatorname{IgA})$ in the first seven days.

(Boger et al., 2020; Center for Disease Control and Prevention, 2020e; Younes et al., 2020). 
Table 9.

2019-2020 US Flu Season Data

\section{9-2020 U.S. Flu Season: Preliminary Burden} Estimates

CDC estimates* that, from October 1, 2019, through April 4, 2020, there have been:
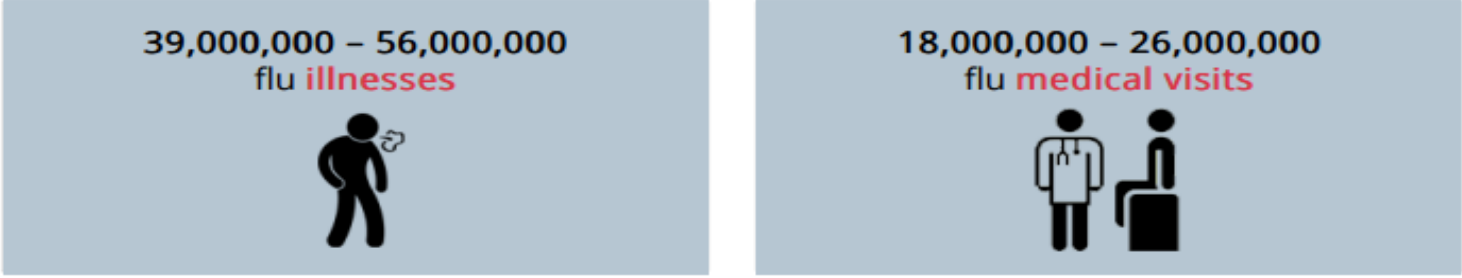

$410,000-740,000$

flu hospitalizations

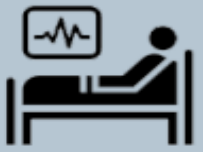

$24,000-62,000$ flu deaths

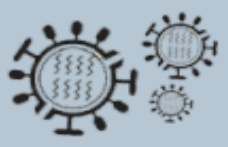

NOTE: The week of April 4 was the last week in-season influenza burden estimates will be provided for the 2019-2020 season. 


\section{Figure 1.}

Global Trend of COVID-19 from February to September 2020

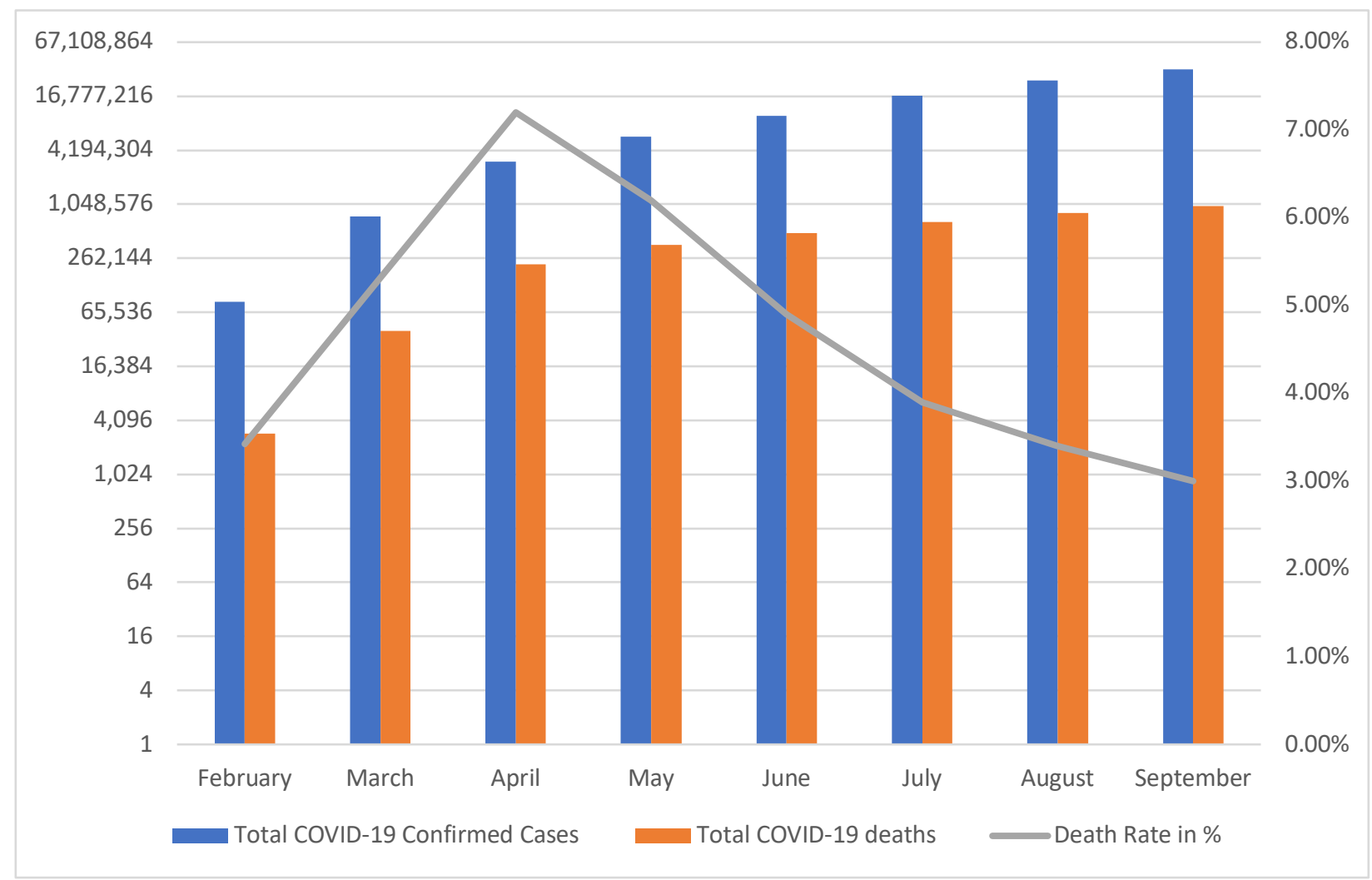

(World Health Organization, 2020e) 
Figure 2.

Death Rate by WHO Region as of October 17, 2020

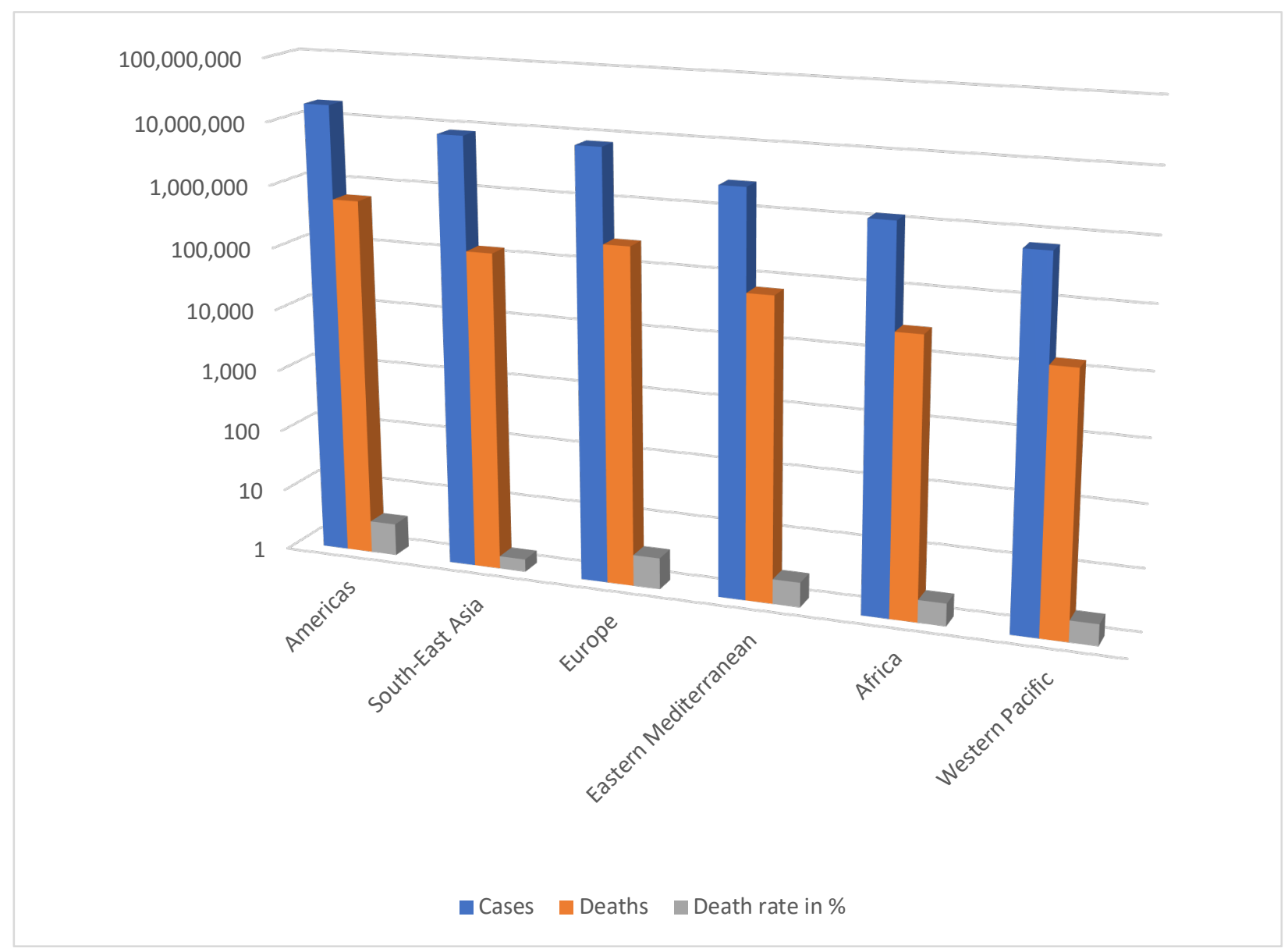

(World Health Organization, 2020e) 
Figure 3.

COVID-19 Confirmed Cases by WHO Region from February to September 2020

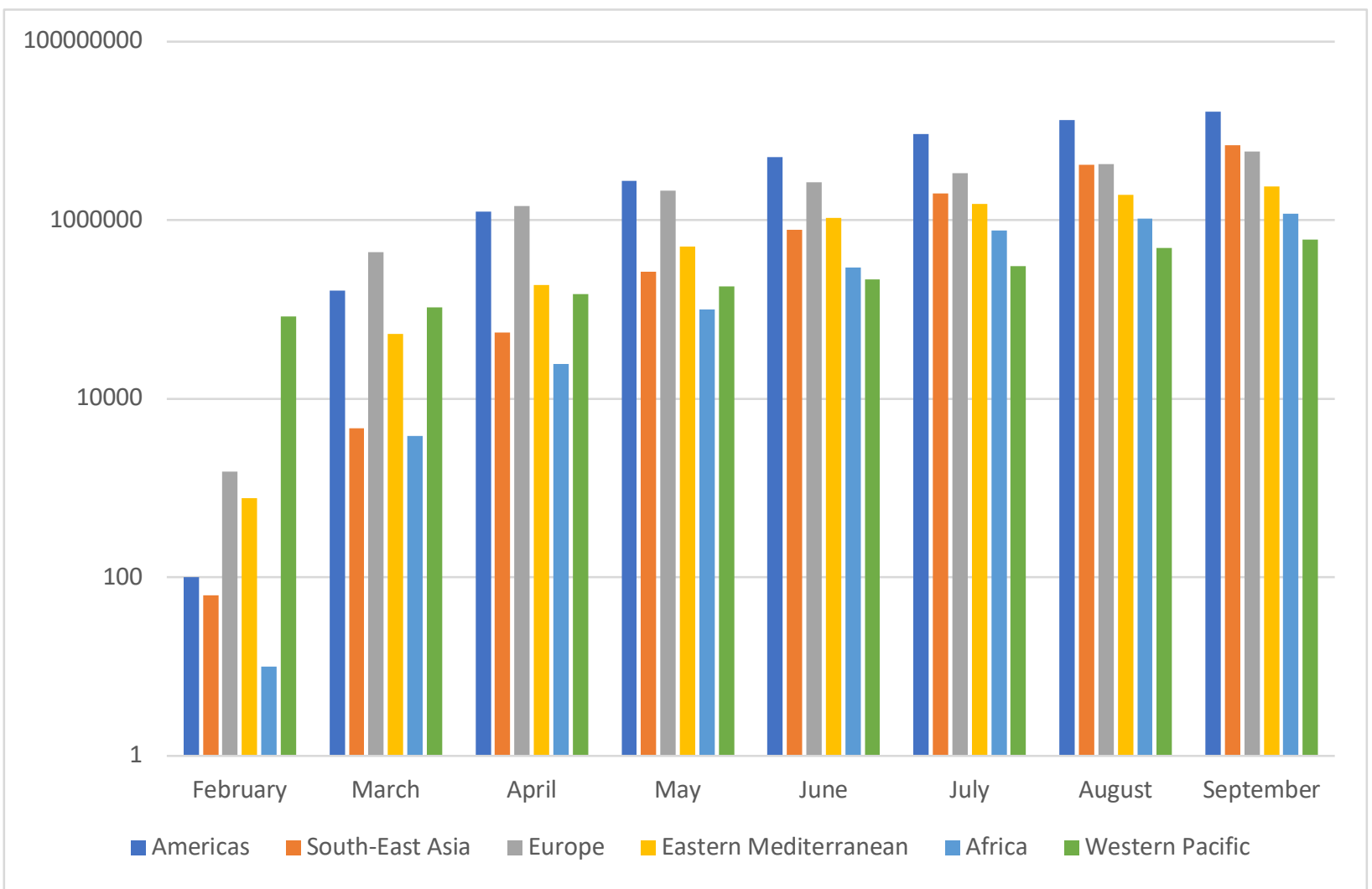

(World Health Organization, 2020e) 


\section{Figure 4.}

COVID-19 Deaths by WHO Region from February to September 2020

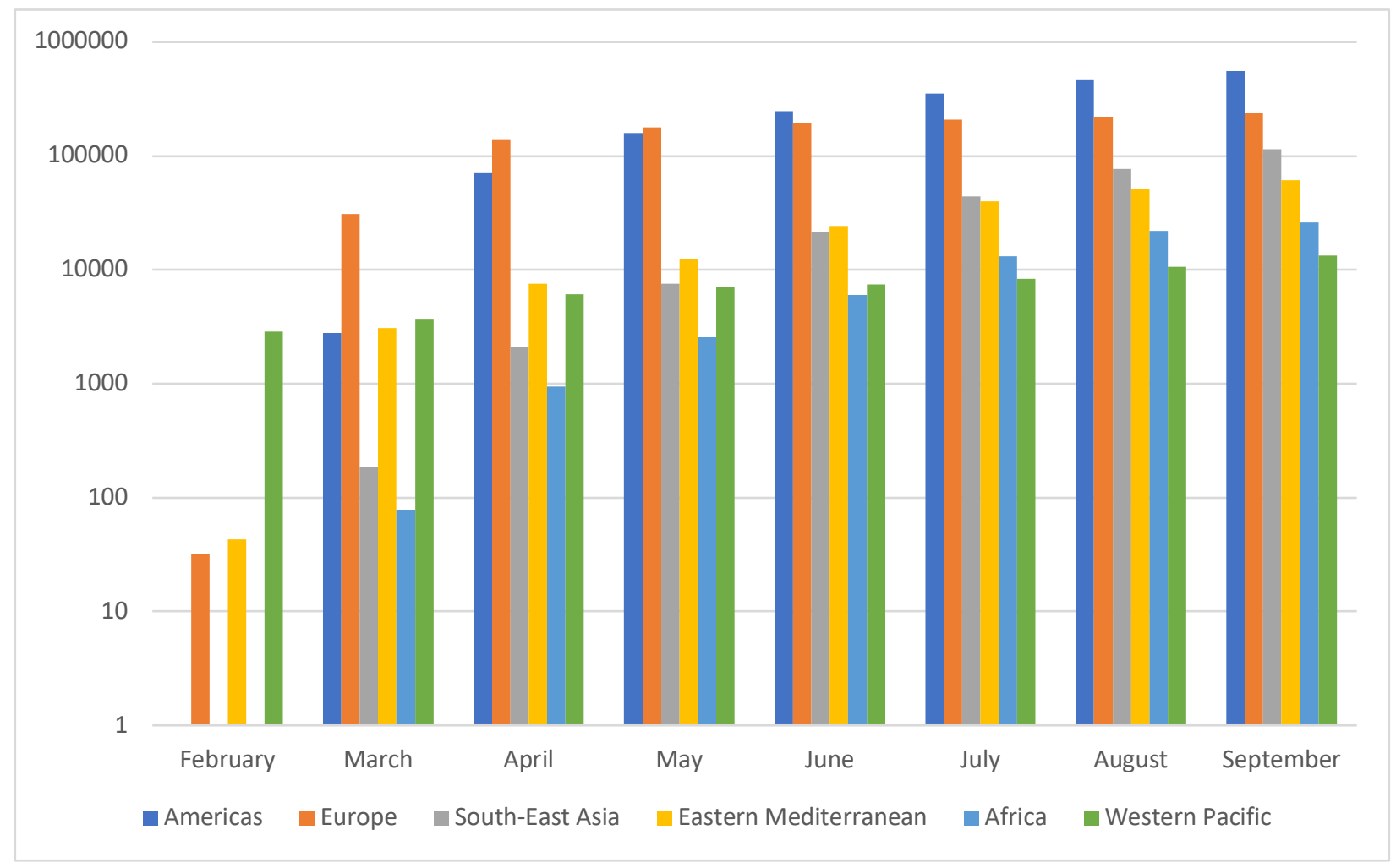

(World Health Organization, 2020e) 


\section{Figure 5.}

\section{COVID-19 Trend in Confirmed Cases: Top 12 Countries from February to September}

\section{0}

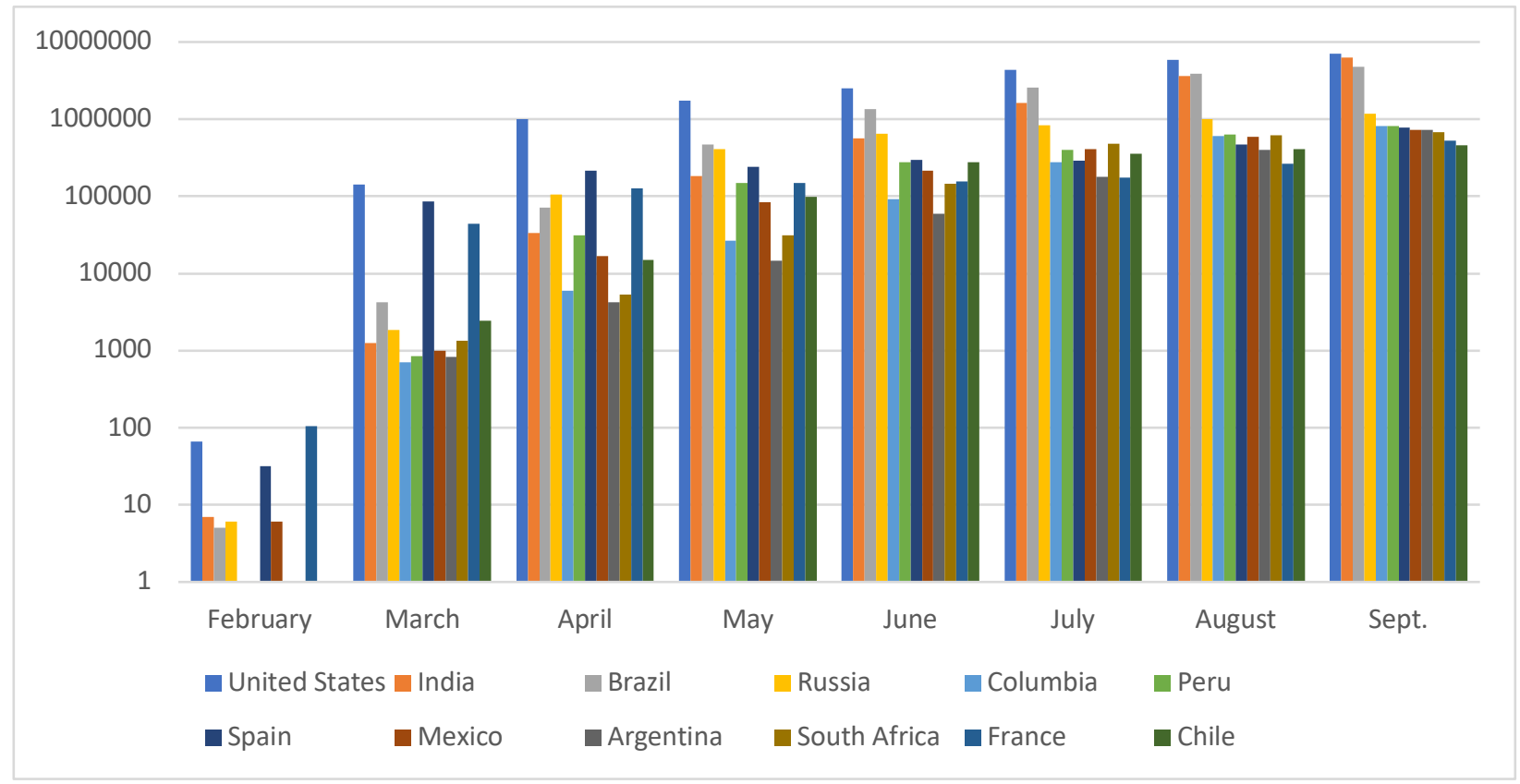

(World Health Organization, 2020e) 


\section{Figure 6.}

COVID-19 Trend in Most Deaths: Top 12 Countries from February to September 2020

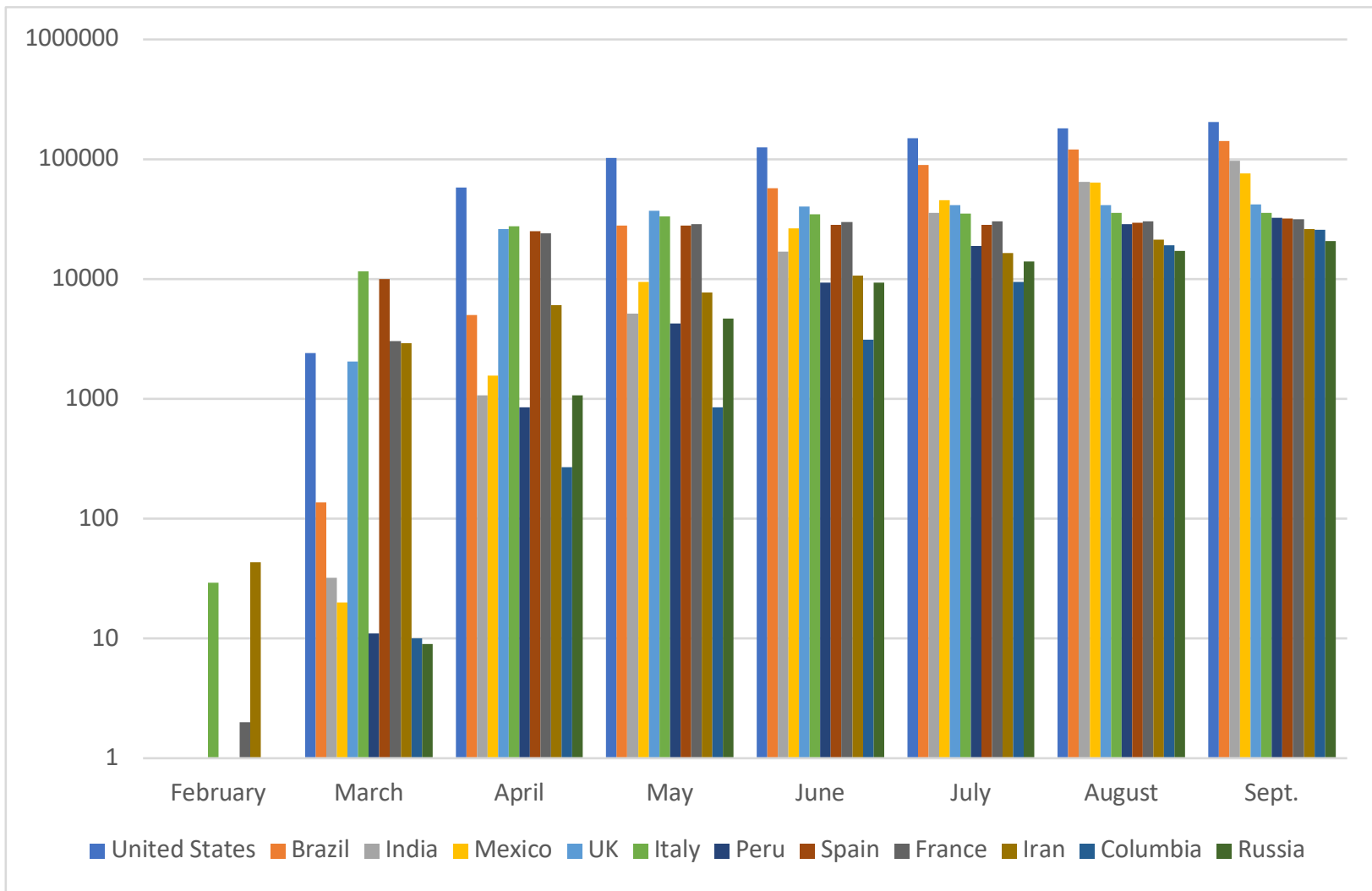

(World Health Organization, 2020e) 


\section{Figure 7.}

\section{COVID-19 Coinfection Respiratory Pathogens}

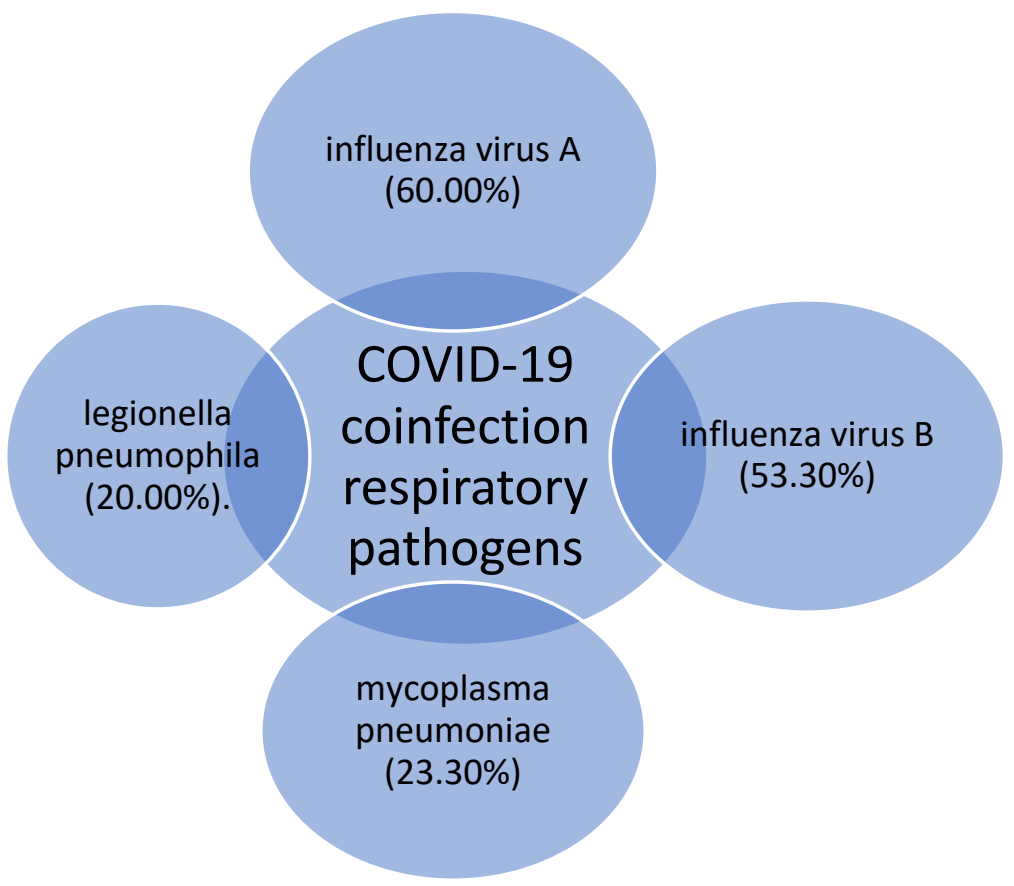

(Xing et al., 2020) 
Figure 8.

Big Picture Illustration

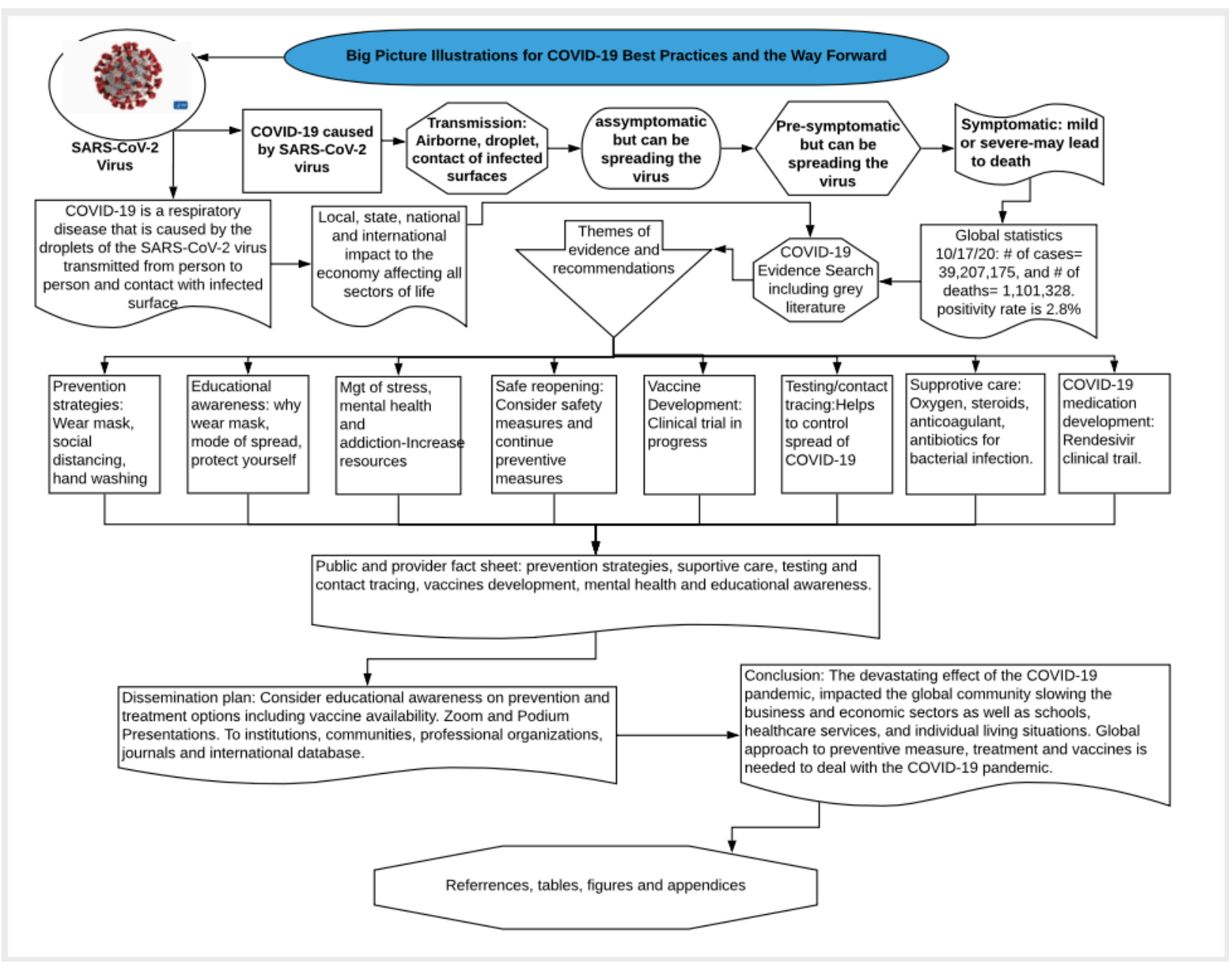




\section{Figure 9.}

\section{Types of Immunity}

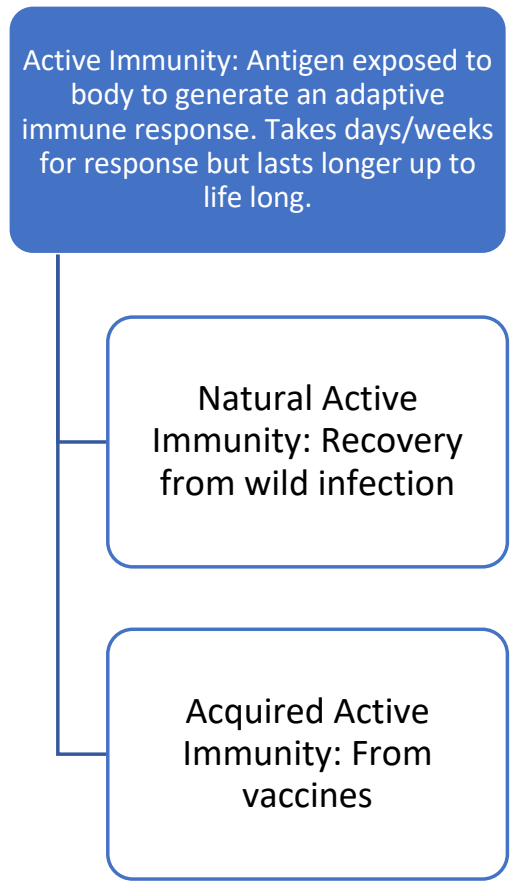

Passive Immunity: IgG antibodies

provided to the body to protect

against infection. Response ie

immediate but lasts shorter for

several weeks to upt to four months.

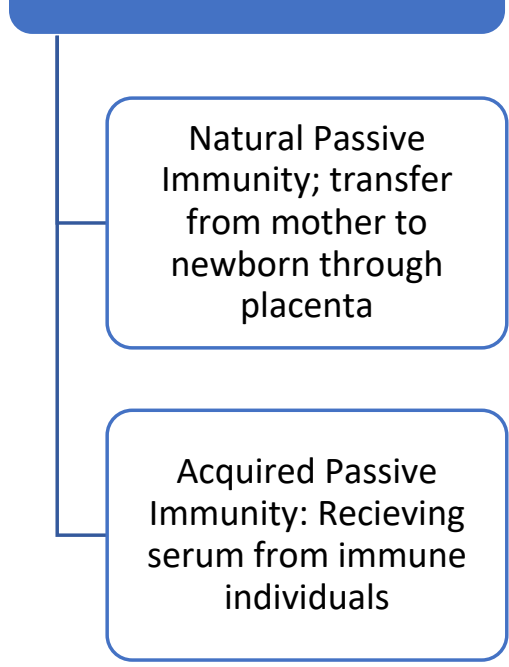

(Center for Disease Control and Prevention, 2020d) 


\section{Figure 10.}

\section{COVID-19 Public Fact Sheet}

\section{COVID-19 PUBLIC FACT SHEET}

COVID-19: An infection caused by Nova coronavirus (SARS-CoV-2)
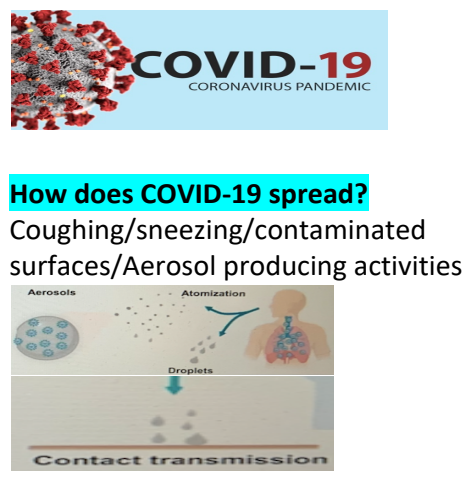

What are the symptoms? Appears two to 14 days after exposure

\begin{tabular}{|c|c|}
\hline FEVER & DIFFICULTY BREATHING \\
\hline COUGH & LOSS OF TASTE/SMELL \\
\hline MUSCLE ACHES & SEVERE ILLNESS \\
\hline
\end{tabular}

How to Slow the Spread of COVID-19
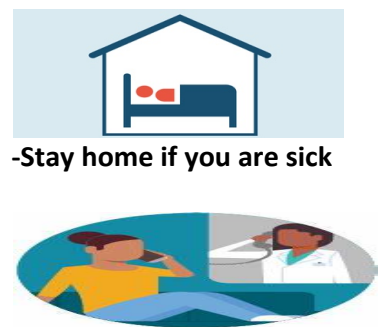

-Call before visiting your healthcare provider

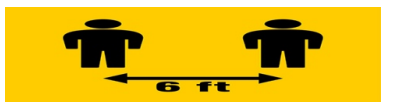

-Maintain 6 feet social distancing
How to Slow the Spread of COVID-19
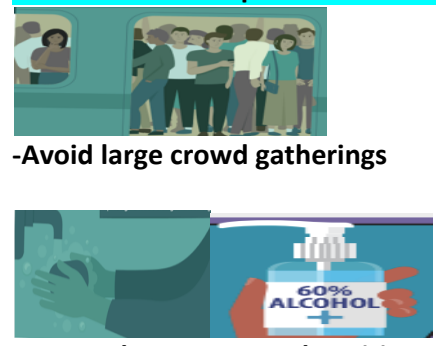

Soap and water Hand Sanitizer -Wash hands frequently

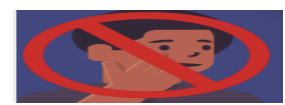

-Avoid touching face with unwashed hands
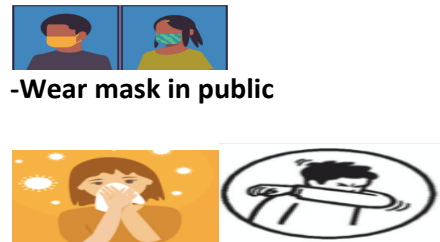

-Cover your cough and sneeze/ use your elbow
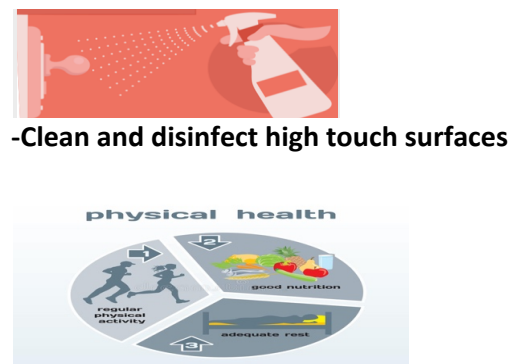

-Get adequate sleep, rest, and eat a wellbalanced meal

For More Information See CDC.gov 


\section{Figure 11.}

\section{COVID-19 Healthcare Provider Fact Sheet}

\section{COVID-19 HEALTHCARE \\ PROVIDER FACT SHEET \\ Prevention}

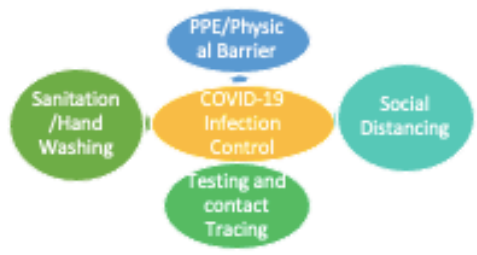

\section{Severity and Risk Factors}

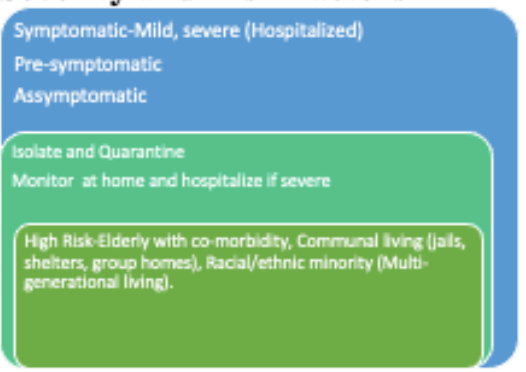

\section{Supportive Care}
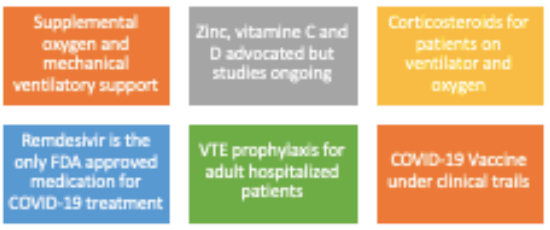

Immunotherapy

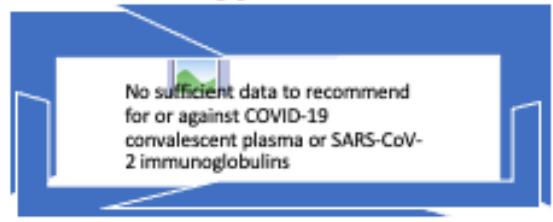

CDC (2020).

https://www.cdc.gov/coronavirus/2019-

ncov/hcp/therapeutic-options.html NIH (2020). https://www.covid19 treatmentguidelines.nih.gov/

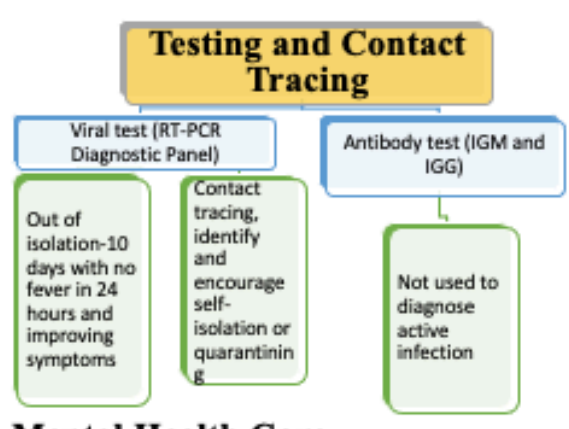

Mental Health Care

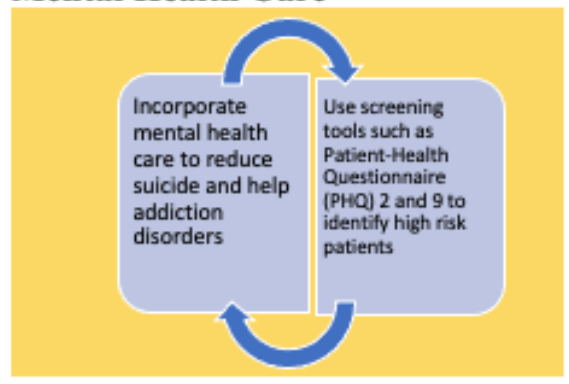

Telemedicine

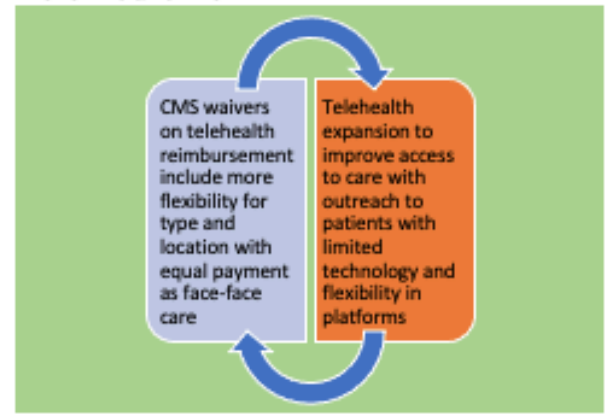

\section{Education}
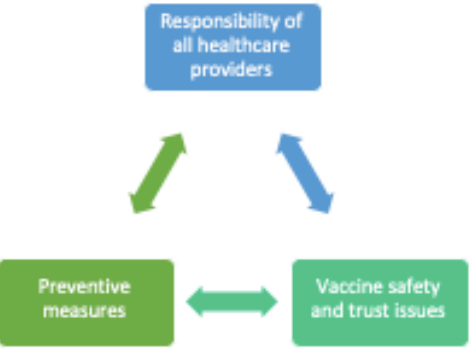


\section{Appendix A.}

\section{Evidence Review Table}

\begin{tabular}{|c|c|c|c|}
\hline Citation & Themes & Outcome and Key Findings & $\begin{array}{l}\text { Design, Level, } \\
\text { Quality Grade }\end{array}$ \\
\hline $\begin{array}{l}\text { Ahmed, S., Quadeer, A., } \\
\text { \& McKay, M. (2020). }\end{array}$ & $\begin{array}{l}\text { Vaccine } \\
\text { production }\end{array}$ & $\begin{array}{l}\text { Preliminary identification of potential } \\
\text { vaccine targets for the COVID-19 } \\
\text { coronavirus. }\end{array}$ & Level III, Grade B. \\
\hline $\begin{array}{l}\text { Anderson, Heesterbeek, } \\
\text { Klinkenberg, \& } \\
\text { Hollingsworth (2020). }\end{array}$ & $\begin{array}{l}\text { Prevention } \\
\text { strategies. } \\
\text { Vaccine } \\
\text { limitation }\end{array}$ & $\begin{array}{l}\text { A personal effort will help in the } \\
\text { prevention of the spread of COVID- } 19 \text {. } \\
\text { The big issue in vaccine development } \\
\text { remains the site for phase three trial and } \\
\text { manufacturing at the required scale }\end{array}$ & $\begin{array}{l}\text { Supplemental article } \\
\text { from Elsevier Public } \\
\text { Health Emergency } \\
\text { Collection. }\end{array}$ \\
\hline $\begin{array}{l}\text { Ashour, Elkhatib, } \\
\text { Rahman, \& Elshabrawy, } \\
(2020) \text {. }\end{array}$ & $\begin{array}{l}\text { Prevention } \\
\text { strategies and } \\
\text { Testing }\end{array}$ & $\begin{array}{l}\text { Hand washing and a quick diagnostic test. } \\
\text { How treatment and preventive strategies } \\
\text { are implemented determines the future of } \\
\text { COVID-19. }\end{array}$ & $\begin{array}{l}\text { Case report article, level } \\
4 \text {, quality grade B }\end{array}$ \\
\hline $\begin{array}{l}\text { Bajwah, Wilcock, } \\
\text { Towers, Costantini, } \\
\text { Bausewein, Simon, } \\
\text { Bendstrup, ... } \\
\text { Higginson, (2020). }\end{array}$ & $\begin{array}{l}\text { Supportive } \\
\text { treatment }\end{array}$ & $\begin{array}{l}\text { There is a moral obligation to provide } \\
\text { expert symptomatic and supportive } \\
\text { treatment for frail patients with multiple } \\
\text { comorbidities to prevent avoidable } \\
\text { suffering. }\end{array}$ & $\begin{array}{l}\text { Supplemental review } \\
\text { material }\end{array}$ \\
\hline $\begin{array}{l}\text { Canadian Centre for } \\
\text { Occupational Health and } \\
\text { Safety. (2020). }\end{array}$ & Hand washing & $\begin{array}{l}\text { Hand washing as a preventive measure in } \\
\text { controlling infections }\end{array}$ & $\begin{array}{l}\text { Reputable government } \\
\text { agency website }\end{array}$ \\
\hline $\begin{array}{l}\text { Center for Disease } \\
\text { Control and Prevention } \\
(\mathrm{CDC}),(2020)\end{array}$ & $\begin{array}{l}\text { Mental health } \\
\text { and addiction } \\
\text { problems. }\end{array}$ & $\begin{array}{l}\text { Disease outbreaks can increase stress that } \\
\text { ranges from stress regarding personal } \\
\text { health and the health of the loved ones, } \\
\text { eating and sleeping pattern changes with } \\
\text { poor concentration. Increasing stress also } \\
\text { causes worsening of mental health } \\
\text { conditions and increased use of alcohol, } \\
\text { tobacco, and recreational drugs. }\end{array}$ & $\begin{array}{l}\text { Reputable government } \\
\text { agency website }\end{array}$ \\
\hline $\begin{array}{l}\text { Center for Disease } \\
\text { Control and Prevention. } \\
(2020) \text {. }\end{array}$ & $\begin{array}{l}\text { Prevention } \\
\text { strategies }\end{array}$ & $\begin{array}{l}\text { To reduce the spread and prevent } \\
\text { COVID-19, it is recommended that every } \\
\text { individual, community, and the } \\
\text { population at large follow certain } \\
\text { guidelines. }\end{array}$ & $\begin{array}{l}\text { Reputable government } \\
\text { agency website }\end{array}$ \\
\hline $\begin{array}{l}\text { Center for Disease } \\
\text { Control and Prevention. } \\
(2020) \text {. }\end{array}$ & $\begin{array}{l}\text { COVID-19 } \\
\text { Testing }\end{array}$ & $\begin{array}{l}\text { Two types of testing, viral test (to identify } \\
\text { current infection), and antibody testing } \\
\text { (to identify the previous infection). Local } \\
\text { and state health departments and } \\
\text { providers should make decisions about } \\
\text { whom to test. Everyone regardless of the } \\
\text { test result should take preventive } \\
\text { measures. }\end{array}$ & $\begin{array}{l}\text { Reputable government } \\
\text { agency website }\end{array}$ \\
\hline $\begin{array}{l}\text { Center for Disease } \\
\text { Control and Prevention. }\end{array}$ & Vaccine trials & $\begin{array}{l}\text { No vaccine currently for COVID-19, } \\
\text { vaccine trial is still in progress. }\end{array}$ & $\begin{array}{l}\text { Reputable government } \\
\text { agency website }\end{array}$ \\
\hline
\end{tabular}

(2020). 
Fogarty, Townsend, Cheallaigh, Bergin, Martin-Loeches, Browne, Bacon, ... O'Donnell, (2020).

Food and Drug Administration (2020).

Furst, (2020)

Illinois Department of Public Health

Javid, Weekes, \& Matheson, (2020).

Johns Hopkins Medicine. (2020).

Lai, C., Wang, C., \& Hsueh, P. (2020).

Le, Andreadakis, Kumar, Roman, Tollefsen, Saville, \& Mayhew, (2020).

Lodigiani, Lapichino, Carenzo, Cecconi, Ferrazzi, Sebastian, Kucher, ... Barco, (2020). Mayo Clinic. (2020)
Supportive treatment (Thromboembol ic complication of COVID-19 and heparin treatment)

COVID-19 testing

COVID-19 test result

Prevention strategies

Prevention strategies

Prevention strategies

Supportive treatment (Antibiotic treatment of coinfection in COVID-19 patients)

Vaccine development

Supportive treatment (Use of heparin in a hospitalized adult patient)

Plasma treatment trial
Administration of low-molecular-weight heparin in the early phase of COVID-19 treatment may have a positive effect on thrombosis prevention as well as limiting viral infection and reducing systematic and pulmonary inflammation.

Authorized the first diagnostic test with a home collection option for COVID-19 using home-collected saliva samples

The sensitivity and overall test performance characteristics of RT-PCR testing are not yet clearly and consistently reported. This can create a false sense of security with a false negative result.

Avoid close contact by staying at home as much as possible, social distance, and wear masks in public.

Social distancing and wearing a mask to prevent COVID-19 spread

Avoid close contact by staying at home as much as possible, and social distancing. Cover cough and sneezes and wear masks, clean and disinfect frequently touched surfaces, and wear appropriate PPE

There is a possible bacterial co-infection among COVID-19 patients but in a situation where bacterial co-infection cannot be ruled out in COVID-19 patients, the use of empirical antibiotics was recommended for mild cases and a broad-spectrum antibiotic coverage is suggested for severe cases.

The global effort for R\&D for COVID-19 vaccine development in response to the pandemic is unprecedented in the aspects of speed and scale which represents a huge change from the traditional vaccine development pathway of five to ten years.

Administration of low-molecular-weight heparin in the early phase of COVID-19 treatment may have a positive effect on thrombosis prevention as well as limiting viral infection and reducing systematic and pulmonary inflammation.

Use of ABO compatible convalescent plasma treatment where the plasma of a person that has recovered from laboratory documented infection with SARS-CoV-2 is in the trial phase. The plasma from a recovered patient is believed to contain
Retrospective study

Reputable government agency website

Peer review medical journal article from a reputable healthcare organization

Reputable government site

Grey literature from a reputable healthcare organization

A systematic review of cross-sectional studies

Prospective study

Retrospective cohort study

Grey literature from a reputable healthcare organization 
National Institutes of

Health (2020);

Center for Disease

Control and Prevention. (2020).

Pan, Chen, Xia, Wu, Li,

Ou, Zhou, \& Liu, (2020)

Srivastava, \& Saxena, (2020).

Thachil, (2020).

Tulchinsky, T. H., \&

Varavikova, E. A.

(2014).

West, Montori, Sampathkumar, (2020).

World Health

Organization

Zhang, Zhao, Zhang,

Wang, Li, Liu, Wang, ... Zhang, (2020).

Zitek, (2020).
Treatment guideline, antiviral, and

immune-based therapy trial.

Contact tracing

Prevention strategies, and vaccine trial progress

Supportive treatment (Use of lowmolecularweight heparin)

Vaccine and plasma treatment trials

COVID-19 testing and the false negative result

Prevention strategies

Supportive treatment (Antiinflammation therapy in COVID-19 patients)

COVID-19 testing antibodies that will fight against the COVID-19.

Antiviral medication-on trial phase. Immune-based therapy 1) Convalescent Plasma and Immune Globulins), 2) Interleukin-6 Inhibitors- Both under evaluation.

Antithrombotic therapy-Recommended for prevention of venous thromboembolic events in adult hospitalized patients per standard.

Asymptomatic family members and close contact of infected individuals can be spreading the virus.

COVID-19 virus is a person-to-person transmission. The precautionary measures and efficient health response from governments, healthcare personnel, and the public can only prevent COVID-19 infection from spreading. different vaccine trials are in progress.

Administration of low-molecular-weight heparin in the early phase of COVID-19 treatment may have a positive effect on thrombosis prevention as well as limiting viral infection and reducing systematic and pulmonary inflammation.

Immune-based therapy and development of vaccines for COVID-19. For vaccines development, effectively killed or attenuated organisms, or parts of organisms are introduced as antigens into the body, which response by producing antibodies as active acquired immunity.

This study added that the false-negative result carries great consequences of relaxing personal prevention strategies and increasing the spread of COVID-19 especially among asymptomatic people,

Some simple precautions can help in preventing the spread of COVID-19

The use of anti-inflammation therapy initiated at the right time is very important to achieve the most favorable effects.

Recommended the appropriate use of testing for COVID-19 and not overrelying on the test result. RT-PCR nasopharyngeal swab test that is negative is insufficient to rule out COVID-19.
Reputable government agency website

Observatory study, evidence level III, quality grade B.

Journal review

Retrospective cohort study

Evidence level III, quality grade B.

Expert correspondence from a reputable healthcare organization.

International healthcare agency site

Retrospective observational study

Evidence level 1, quality grade $\mathrm{A}$ 
Legend: RT-PCR-Reverse transcriptase-polymerase chain reaction; R\&D-Research and development 